\title{
THE BEHAVIOUR AND DESIGN OF LAP-JOINTS IN THIN-WALLED BAR CONSTRUCTIONS
}

\author{
W. Wuwer ${ }^{1}$ \\ ${ }^{l}$ Associate Professor, D.Sc., PhD. Eng., Faculty of Civil Engineering, \\ Department of Building Structures, Silesian University of Technology, Gliwice, Poland \\ (Corresponding author: E-mail: Walter.Wuwer@polsl.pl)
}

Received: 12 March 2007; Revised: 2 May 2007; Accepted: 3 August 2007

\begin{abstract}
The paper presents the results of checking experimentally the way of calculating an m-bolt single-cut joint with blind-bolts, dealt with by Wuwer [1,2]. The method of calculating any arbitrary lap-joint was checked there by testing symmetrical five-blind-bolt and eight-blind-bolt joints of cold-bent profiles, the walls of which were $5.0 \mathrm{~mm}$ thick, respectively: stretched eccentrically and alternately bent. The present report, however, deals with the results of investigations on test elements with asymmetrical four-blind-bolt joints of walls, $4.0 \mathrm{~mm}$ thick, which were simultaneously subjected to bending and shearing. In all the three kinds of joints single-cut blind bolts type BOM-R16-4 were used [3]. Loads increasing proportionally until the destruction of the joint, were reiterated cyclically on stabilized levels. The set of equations describing the static behaviour of a joint was solved numerically, and the results were compared with the results of experimental investigations. For the bolt subjected to the highest effort in the 4-blind-bolt joint boundary curves of the load-carrying capacity were plotted for three cases of boundary states I, II and III. Moreover, the boundary curve of the load-carrying capacity was determined for the boundary state I. Basing on the example of a frame with flexible joints attempts have been made as well to assess the influence of interactive connections between three rigidities in a lap-joint, combined with a rotation and two shifts (perpendicular to each other) between the joined walls of sheet-metal sections. Each of the three instantaneous rigidities has been expressed by the coefficient of rigidity reduction and the parameter of rigidity degradation, depending on the quantities acting in the joint of the loads $M, V$ and $H$.
\end{abstract}

Keywords: sheet-metal section; single-cut joint; instantaneous centre of rotation; rotational friction; boundary curve of the load-carrying capacity; instantaneous rigidity; coefficient of rigidity reduction; rigidity degradation

\section{INTRODUCTION}

The correctness of the method of calculating single-cut lap-joints of thin walls with blind bolts was checked experimentally on the example of three different single-cut lap-joints (Figure 1):

a) a symmetrical 5-blind-bolt joint of walls, $5.0 \mathrm{~mm}$ thick, presented by Wuwer [1],

b) a symmetrical 8-blind-bolt joint of walls, $5.0 \mathrm{~mm}$ thick, presented by Wuwer [2],

c) an asymmetrical 4-blind-bolt joint of walls, $4.0 \mathrm{~mm}$ thick, presented by Wuwer [4].

All the joints in the test elements consisted of five, eight and four blind bolts, type BOM R16, class 12.9, with a diameter of $d=13.6 \mathrm{~mm}$ [3]. In the case of walls with a thickness of $5.0 \mathrm{~mm}$ the blind bolts were mounted in holes $\varnothing 14.0 \mathrm{~mm}$ in diameter, whereas in the case of walls with a thickness of $4.0 \mathrm{~mm}$ the diameter of the holes amounted to $14.3 \mathrm{~mm}$. Steel profiles with walls 4.0 and $5.0 \mathrm{~mm}$ thick were made of the same kind of steel: St3SX (according to Polish standard), S235 JR (according to Eurocode 3). The technology of joining permitted, according to the recommendations of their producer, holes with diameters of $13.8 \div 14.8 \mathrm{~mm}$. After the bolt had been inserted by means of a so-called embedder, it was quite tight (Figure 2). With the growing load, the bolts were gradually tilted, and they began to work in a complex state of stresses.

All the numerical calculations were carried out by Dr Ryszard Walentynski from the Chair of the Theory of Designing, Silesian University of Technology, by means of the programme Mathematics, among others in Reference [5]. These calculations consisted in the solution of a set of $(m+3)$ equations, describing the static behaviour of a joint comprising three equations of equilibrium and $m$ physical equations, formulated by means of the geometrical connections in the joint, where $m-$ 
number of the blind bolts in the joint. A physical (constitutive) equation was the anti-function versus the exponential dependence $S_{1}-\delta_{L+E}$, which connects the load $S_{1}$ of a single bolt with the mutual displacement $\delta_{L+E}$ of the stretched walls, $4.0 \mathrm{~mm}$ or $5.0 \mathrm{~mm}$ thick, in the single-cut lap-joint.

a)

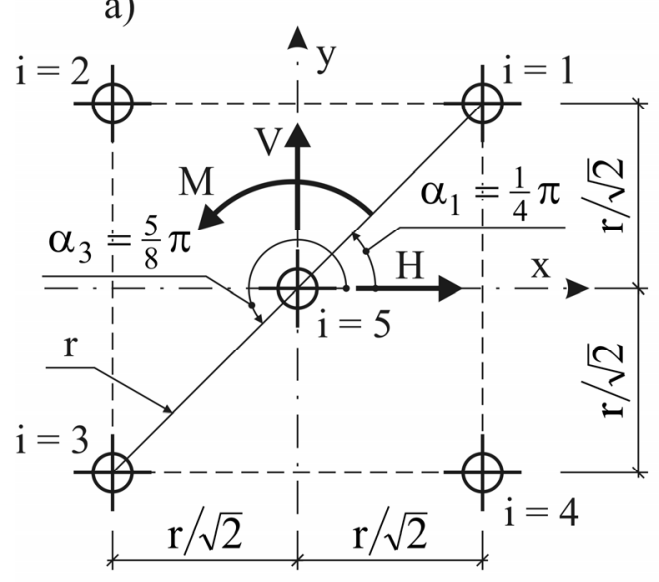

b)

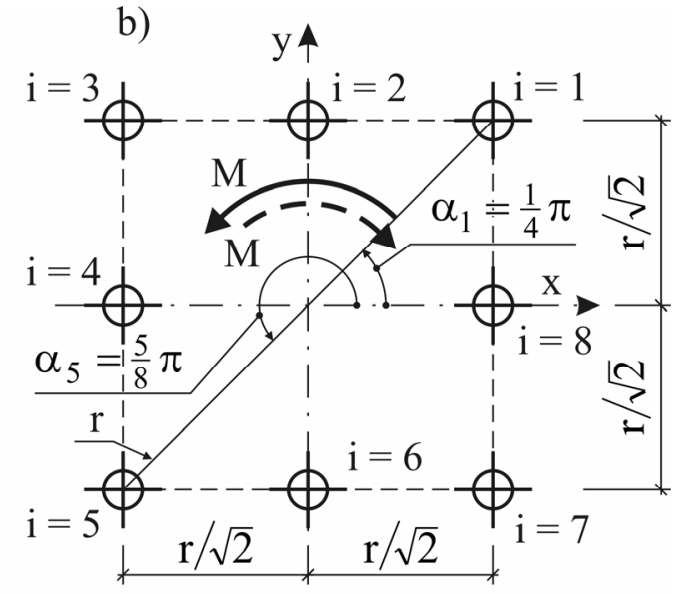

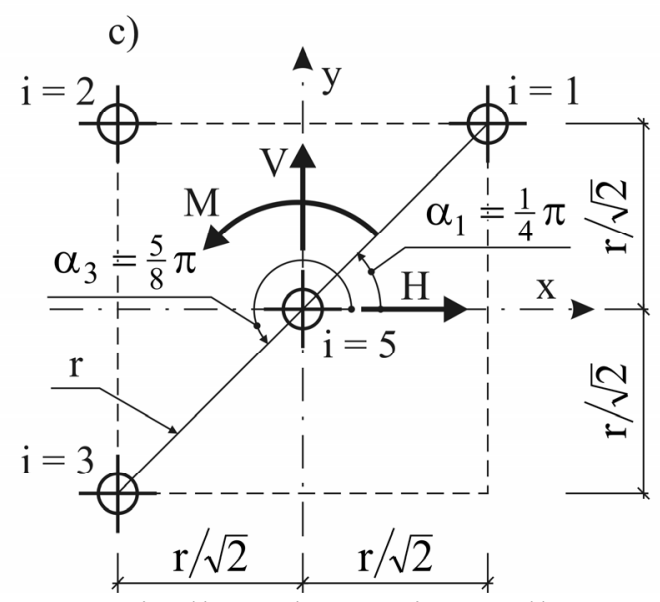

Figure 1. Numerically and Experimentally Tested Joints:

a) Symmetrical Five-blind-bolt Joint of Walls, $5.0 \mathrm{~mm}$ thick,

b) Symmetrical Eight-blind-bolt Joint of Walls, $5.0 \mathrm{~mm}$ Thick,

c) Asymmetrical Four-blind-bolt Joint of Walls, $4.0 \mathrm{~mm}$ Thick

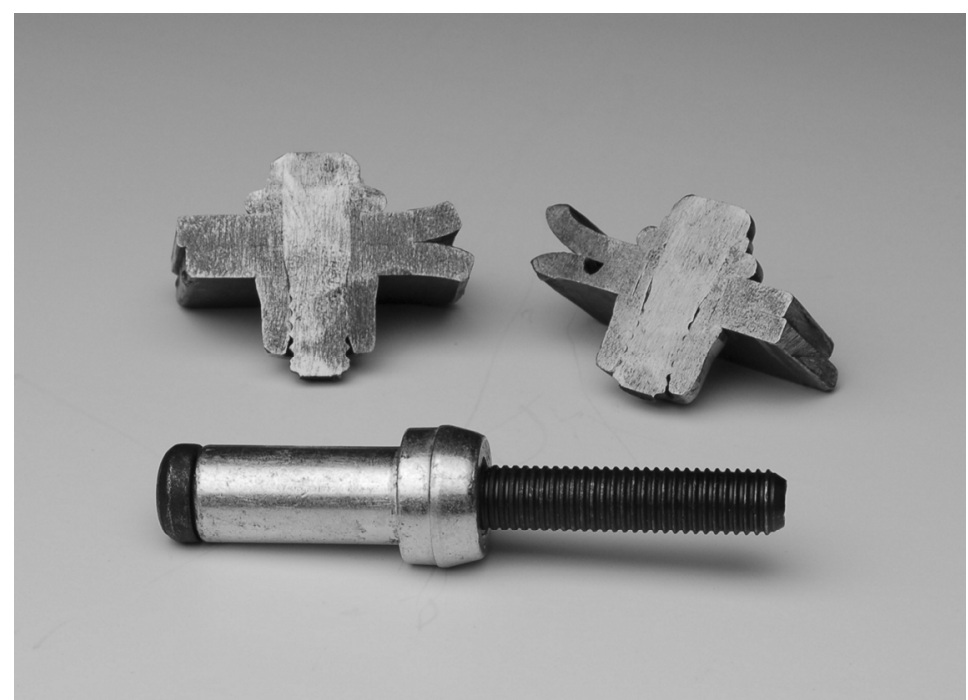

Figure 2. State of the Filling of Holes in Sheet Iron by Bolts 


\section{RESULTS OF INVESTIGATIONS CONCERNING SYMMETRICAL JOINTS}

In two identical experimental elements "V", denoted as V-200,5.1/5 and V-200,5.2/5, a lap joint with five bolts of the type BOM R16-6 (cf. Figure 1a) was cyclically loaded and relieved at various levels of loading $F$. To this joint were transmitted: the shearing force $V=F$ and the bending moment $M=F \cdot e=V \cdot e$ (Figure 3a). The displacements were measured by means of two pairs of dial indicators, mounted on the axes of two connected rods $200 \times 60 \times 5$ (Figure $3 b$ ).

a)

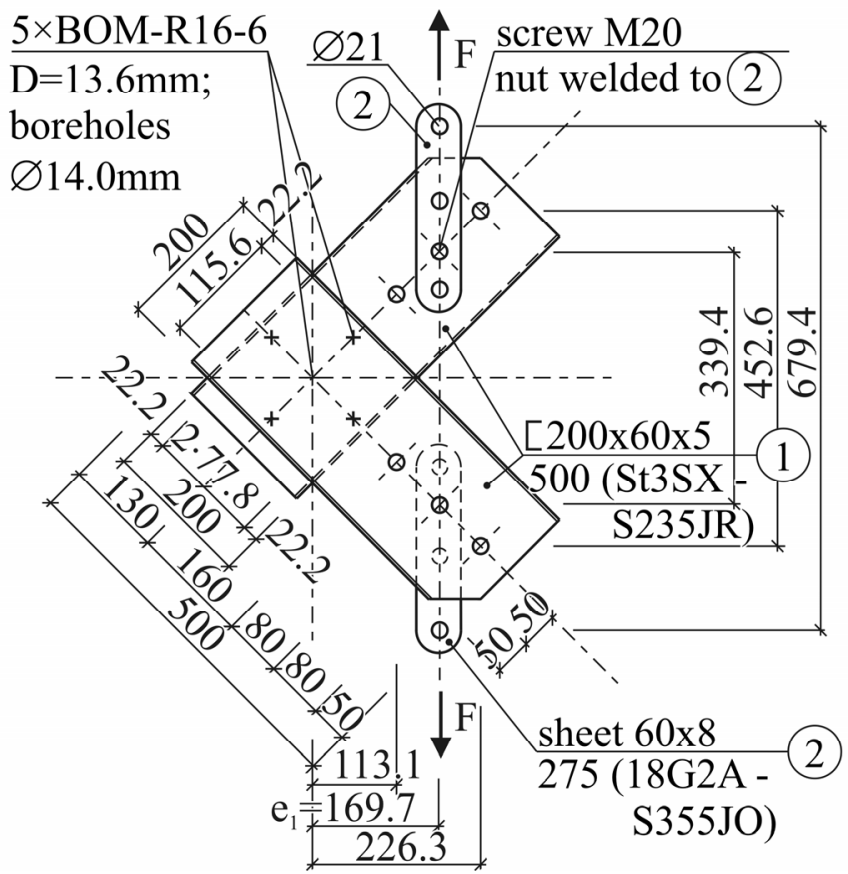

b)

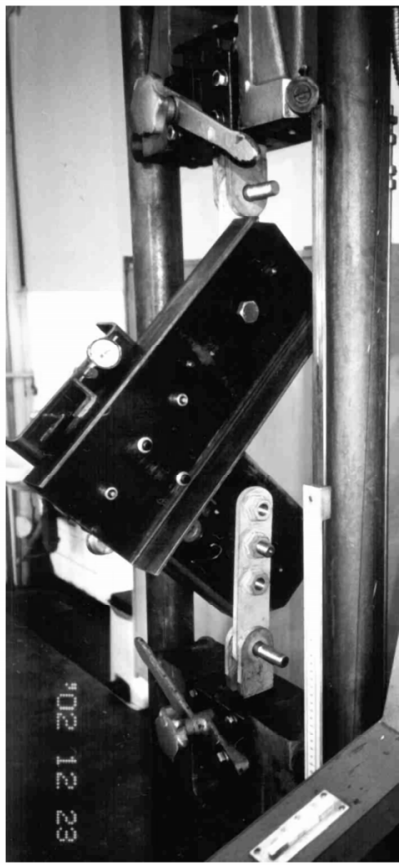

Figure 3. Test Element "V": a) Dimensions, b) View of the Investigated Element, [1]

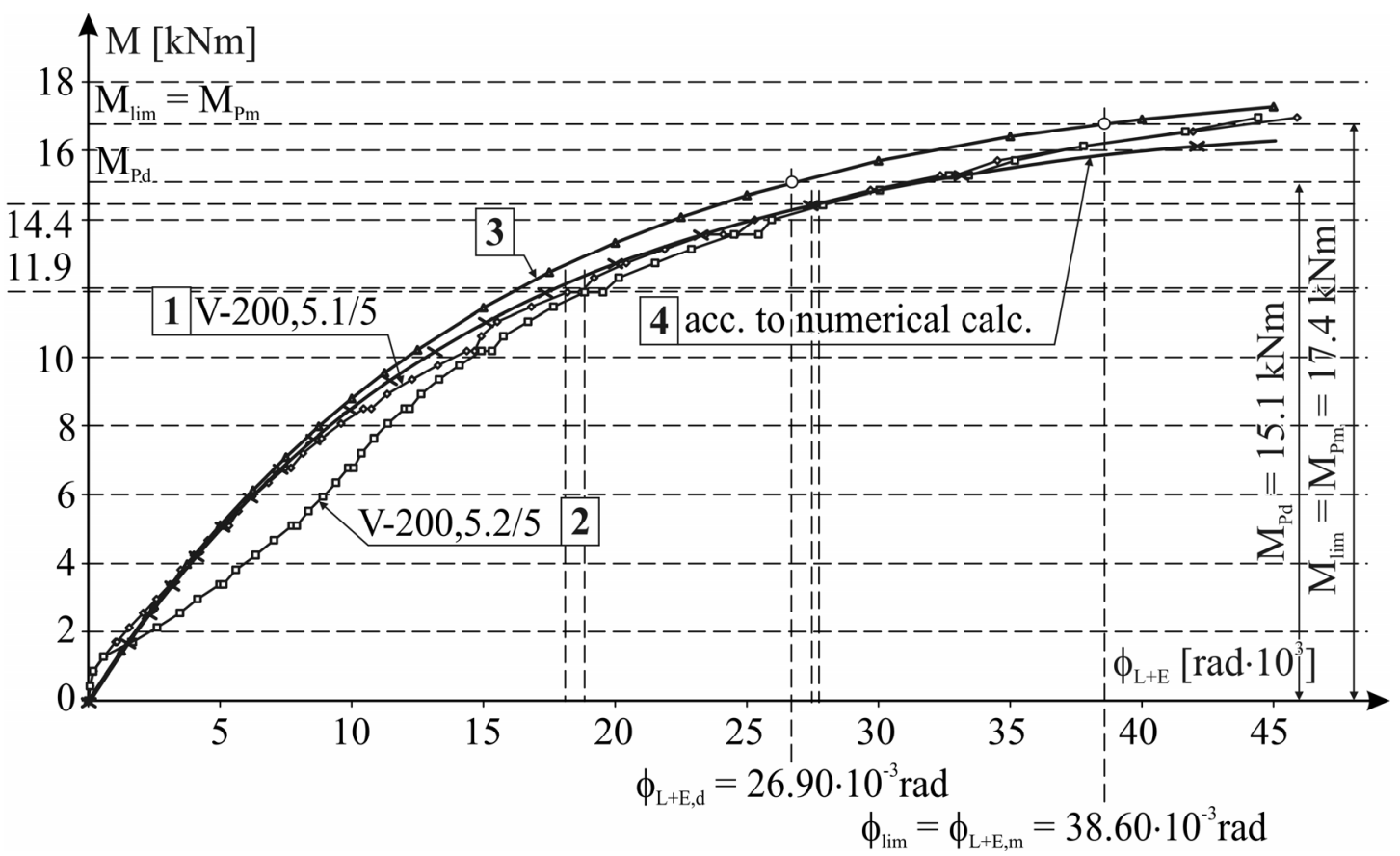

Figure 4. Relation $M-\phi$ : Broken Lines 1 and 2 for Joints in the Test Elements "V", Curve 3 - for Joint Loaded Only by the Moment M, Curve 4 - acc. to Numerical Calc., [1] 
The equations describing the behaviour of a five-blind-bolt joint in the test element "V" were solved numerically by means of the programme "Mathematica". The obtained results of calculations permitted to plot the curve 4 in the diagram $M-\phi$ (Figure 4). The broken lines 1 and 2 correspond to the envelope curves of static equilibrium, obtained in two experimental elements "V". Curve 3 illustrates the behaviour of a five-blind-bolt joint, analogical to the joint tested in the test element "V", but loaded only by the moment $M$.

In two identical test elements, denoted as X-200,5.1/8 and X-200,5.2/8, a eight-blind-bolt joint was tested, loading it cyclically with alternate bending moments $M= \pm \sqrt{2} \cdot b \cdot F$ (Figure 5).

a)

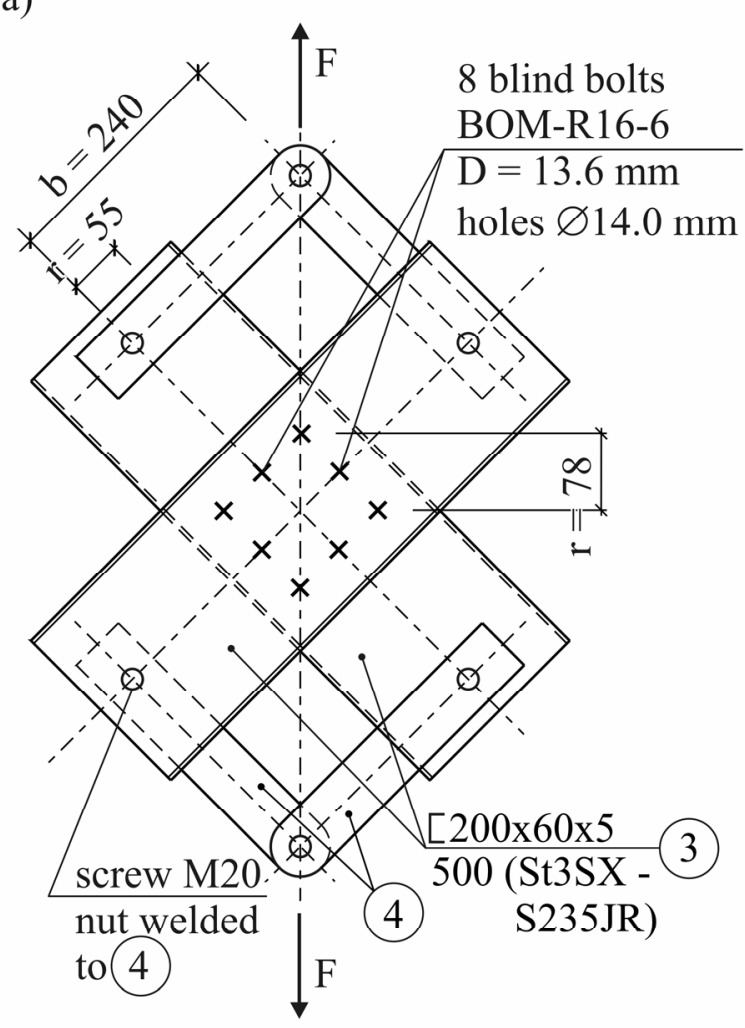

b)

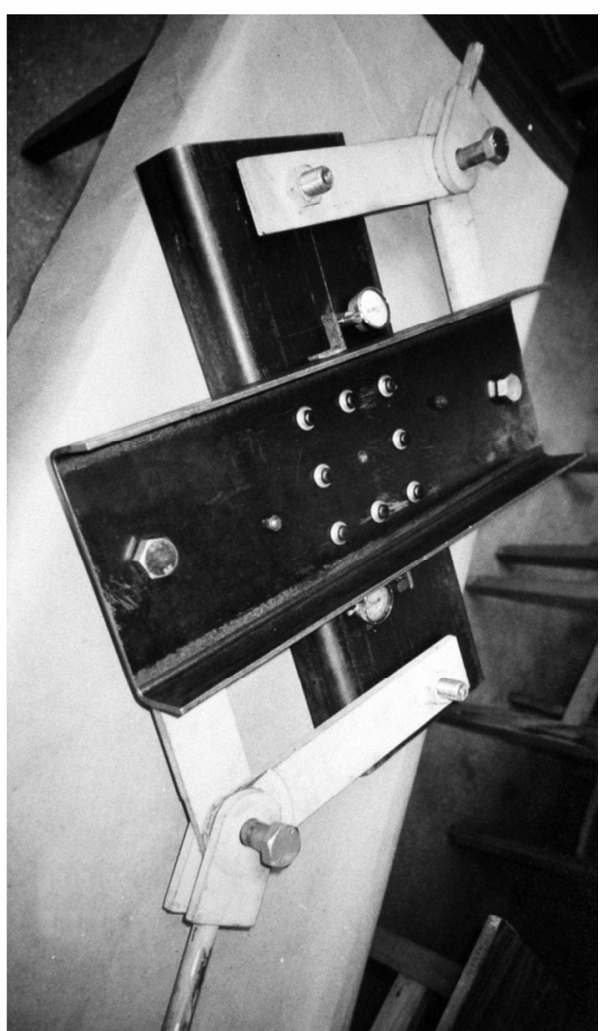

Figure 5. Experimental Element X-200,5.1/8:

a) Construction and Dimensions of the Element, b) Element Anchored in the Testing Machine

The behaviour of these joints is illustrated by two paths of static equilibrium (Figure 6). It is to be noted that in the case of more fasteners in the joint, the envelope curves of the paths of static equilibrium 1 and 2 are more or less similar coinciding better than in the case of 5-blind-bolt joints (cf. Figure 4). We may suppose that when there are more fasteners, the sensitivity to the accuracy of the drilling the holes in the joint is smaller, and so is the sensitivity to the sequence of mounting the blind bolts in the holes.

It is obvious that the investigated eight-blind-bolt are actually more rigid than might be assumed basing on numerical calculations, the results of which were used to plot the curve No. 3 in the diagram. 


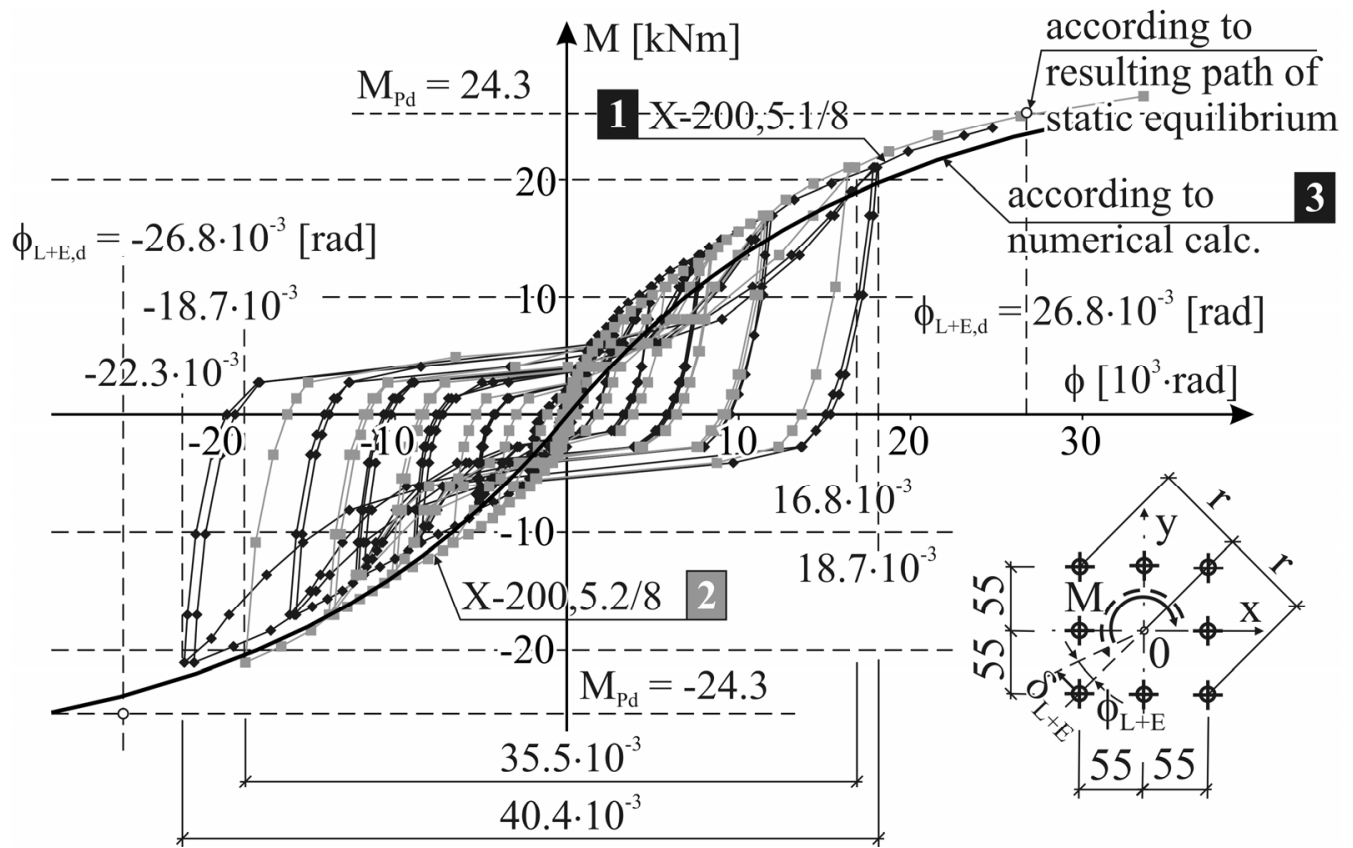

Figure 6. Relation $M-\phi$ of the Eight-blind-bolt Joints in

Experimental Elements X-200,5.1/8 and X 200,5.2/8

\section{THE EFFORT OF AN ASYMMETRIC JOINT WITH FOUR-BLIND-BOLTS OF SHEET-METAL}

\subsection{Experimental Investigations}

In result of experimental investigations:

- the load-carrying capacity of a bolt in a single-cut joint of walls, $4.0 \mathrm{~mm}$ thick, was determined,

- the resulting path of static equilibrium, for the relation $S_{1}-\delta_{L+E}$, was determined,

- three analogical 4-blind-bolt joints were stretched.

In order to determine the calculated load-carrying capacity of a bolt five analogical test elements "I" with a 2-blind-bolt joint, subjected to monotonically increasing axial stretching by the force $F$, were tested. The behaviour of a joint, e.g. in the element I-100, 4.2/2, is demonstrated by the path of static equilibrium in Figure 7.

In compliance with the Recommendations [6] the force which destroys a single bolt in the joint, i.e. the value $S_{1}=P_{m}$ should, be determined as a load which leads to the mutual displacement of the joined walls amounting to $\delta_{\text {lim }}=3.0 \mathrm{~mm}$. In the five tested 2-blind-bolt joints the values of the forces $P$ amounted to $40.84 \mathrm{kN}, 40.26 \mathrm{kN}, 42.12 \mathrm{kN}, 40.75 \mathrm{kN}$ and $37.61 \mathrm{kN}$. Basing on these values the mean boundary value $P_{m \text {,med }}=40.315 \mathrm{kN}$ was found, after which the value of the characteristic load $P_{k}$, was calculated, making use of the formula

$P_{k}=P_{m, \text { med }}-c \cdot s$,

where: $c$ - a coefficient depending on the number of investigated test elements; in the case of five elements it had been assumed to be $c=2.13 ; s$ - standard deflection, calculated in compliance with the guidelines, amounting to $s=1.664 \mathrm{kN}$; thus, according to (1) $P_{k}=40.313-2.13 \cdot 1.654=36.77$ $\mathrm{kN}$. The calculated load-carrying capacity $P_{d}$, of the investigated joint was determined to be equal to $P_{d}=P_{k} / \gamma_{m}$; for the partial factor of safety $\gamma_{m}=1.1$ it amounted to $P_{d}=36.77 / 1.1=33.43 \mathrm{kN}$. 
The doubled values $P_{d}=33.43 \mathrm{kN}$ and $P_{m, m e d}=40.315 \mathrm{kN}$ were plotted in the diagram $F-\delta_{L+E}$ (cf. Figure 7).

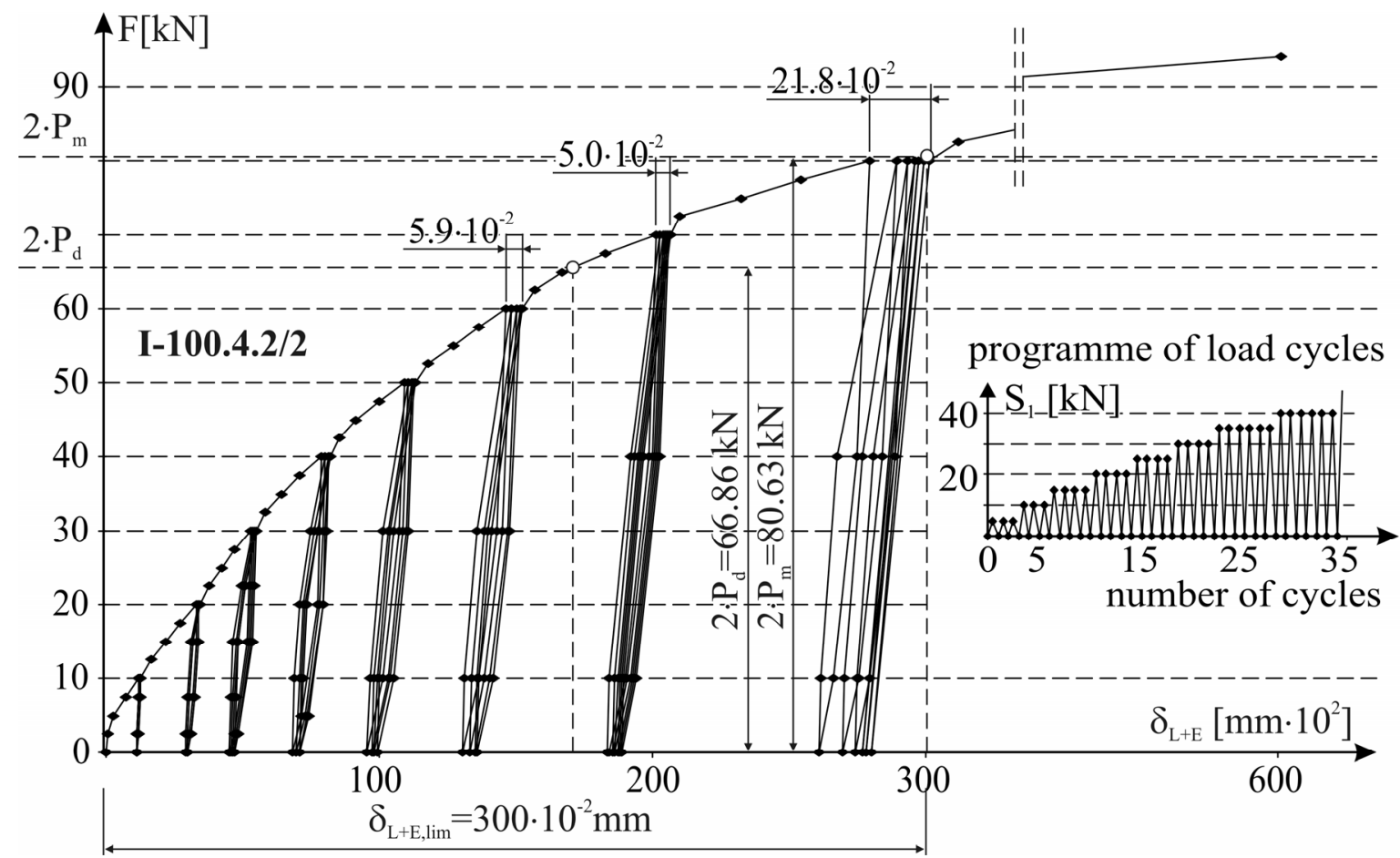

Figure 7. The Path of Static Equilibrium $F-\delta_{L+E}$ for a Joint in the Element I-100, 4.2/2 (36 cycles of loading), [4]

The envelope curves of the paths of static equilibrium, denoted by broken lines, obtained in five test elements "I", were compared in a common diagram of the relation $S_{1-} \delta_{L+E}$ (Figure 8). Making use of; the programme Curve Expert the following exponential function of the regression curve, describing the behaviour of a bolt in the joint, was determined statistically:

$S_{1}=a_{s}\left(1-e^{-b_{s} \cdot \delta_{L+E}}\right)$.

In compliance with Eq. 2 the mutual displacement of the joined iron-sheets equal to $\delta_{L+E, d}=$ $205.7 \cdot 10^{-2} \mathrm{~mm}$, corresponds to the calculated load-carrying capacity of the bolt $P_{d}$. The scattered results are characteristic, particularly the irregular ones in the range of displacements $\delta_{L+E} \leq \delta_{L+E, d}$, i.e. below the calculated load-carrying capacity $P_{d}=33.43 \mathrm{kN}$.

Additionally, a diagram of the relation "load $S_{1}$ - increment of the displacement $\Delta \delta_{L+E}$ " (Figure 9) was plotted, which also proves that the "breakdown" of the load-carrying capacity of the bolt really occurred in the loading range $S_{1}=(30 \div 40) \mathrm{kN}$, containing the load-carrying capacity $P_{d}=33.43$ $\mathrm{kN}$. The values, of the increments of displacements $\Delta \delta_{L+E}$ exerted on each single joint, correspond in the diagram to the increase of the load $\Delta S_{1}$ equal to $5.0 \mathrm{kN}$. 


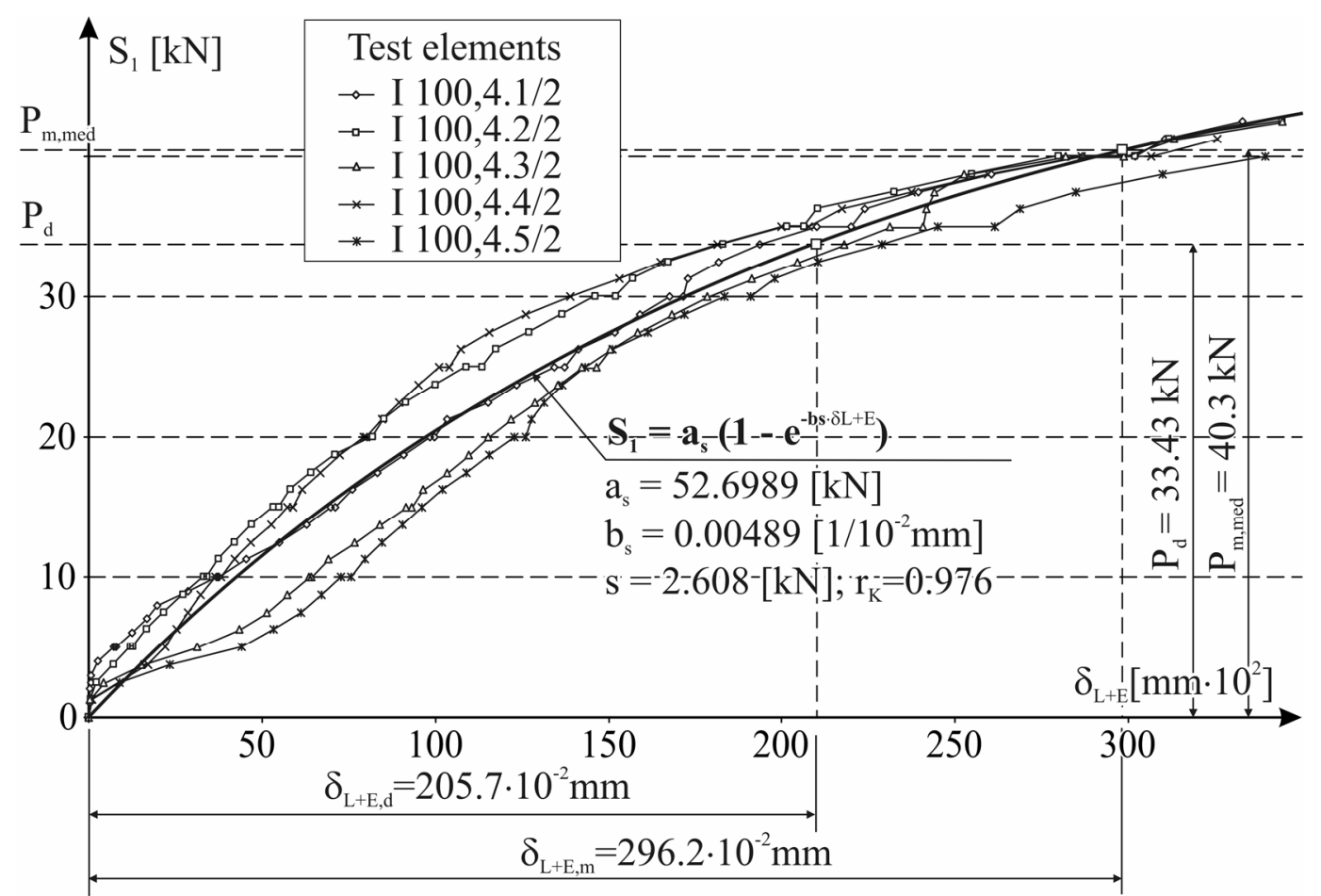

Figure 8. The Relation $S_{1}-\delta_{L+E}$ in the Case of Joining Walls, $4.0 \mathrm{~mm}$ Thick, in Five Elements of the Type "I", [1]

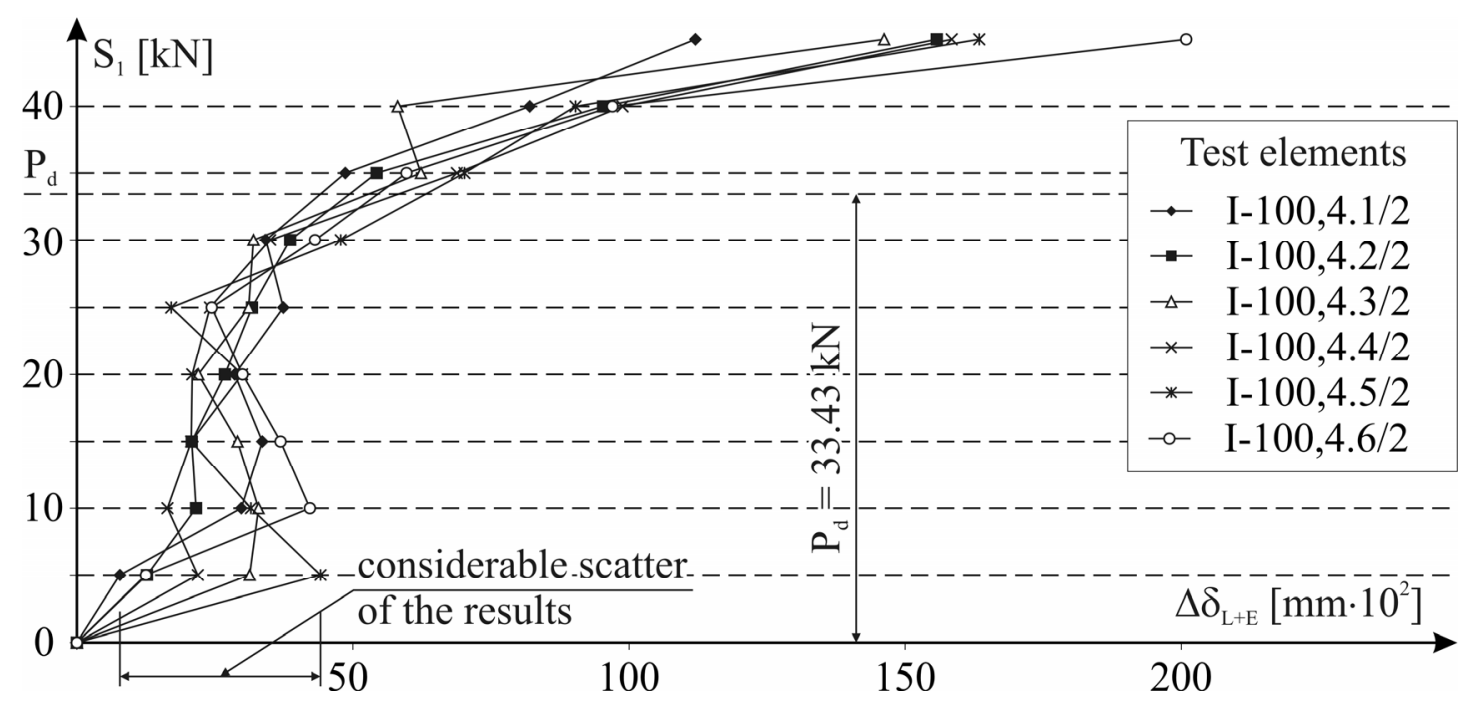

Figure 9. The Dependence $S_{1}-\Delta \delta_{L+E}$ of 2-blind-bolt Joints in Five Test Elements "I", [4]

Similarly, according to Recommendations [6] the calculated load-carrying capacity of the BOM R16-6, joining two walls, $5.0 \mathrm{~mm}$ thick, $P_{d}=48.6 \mathrm{kN}$, as well as its corresponding value of the mutual displacement of the walls $\delta_{L+E, d}=209.3 \cdot 10^{-2} \mathrm{~mm}$, were determined first experimentally and then statically Wuwer [1]. The resulting paths of static equilibrium $S_{1}-\delta_{\mathrm{L}+\mathrm{E}}$ for two tested thickness $4.0 \mathrm{~mm}$ and $5.0 \mathrm{~mm}$ of the walls illustrates diagram on Figure 10. 


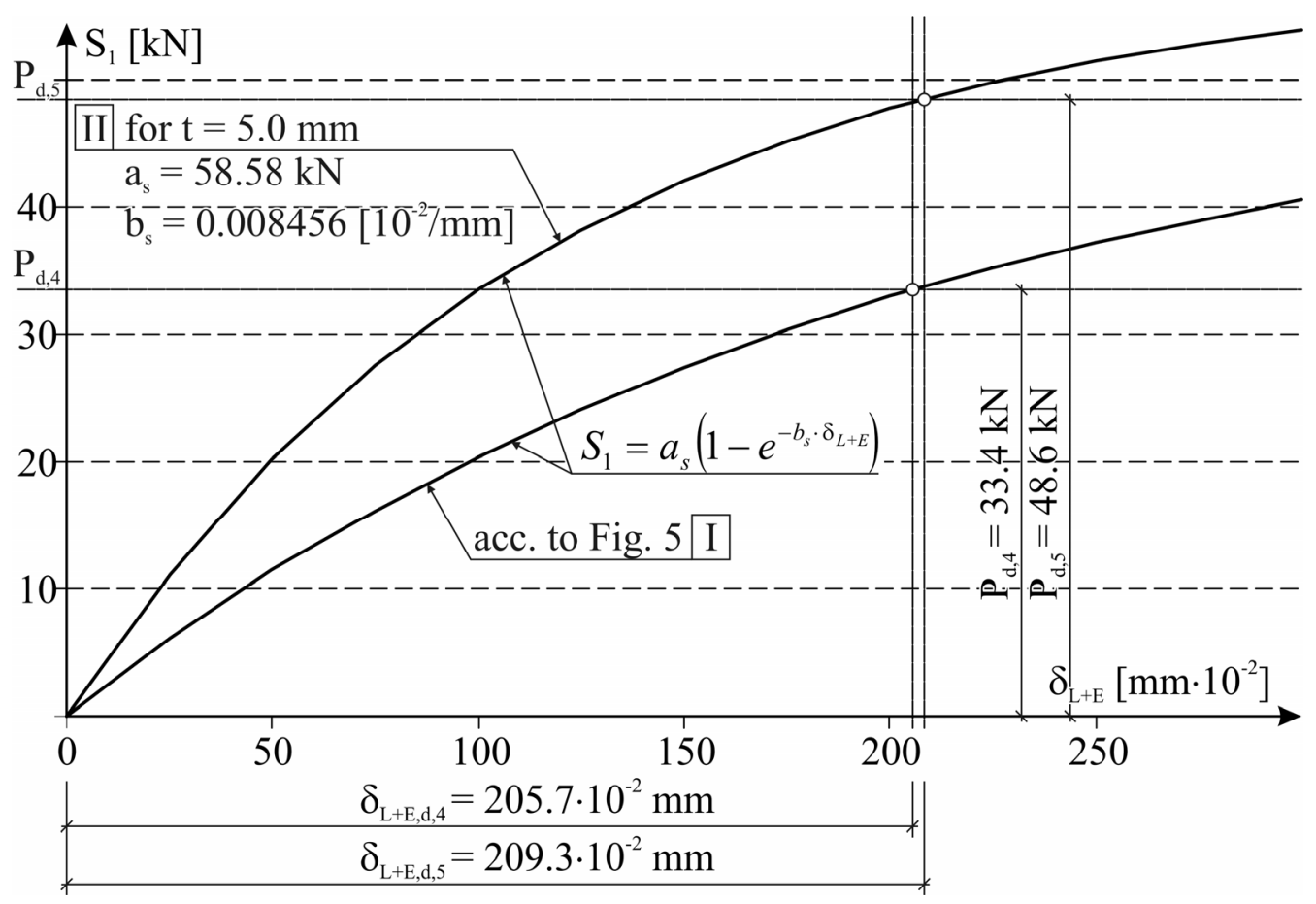

Figure 10. The Resulting Paths of Static Equilibrium $S_{1}-\delta_{L+E}$ : I - for Thickness of the Wall $t=4.0 \mathrm{~mm}$, II - for Thickness of the Wall $t=5.0 \mathrm{~mm}$

a)

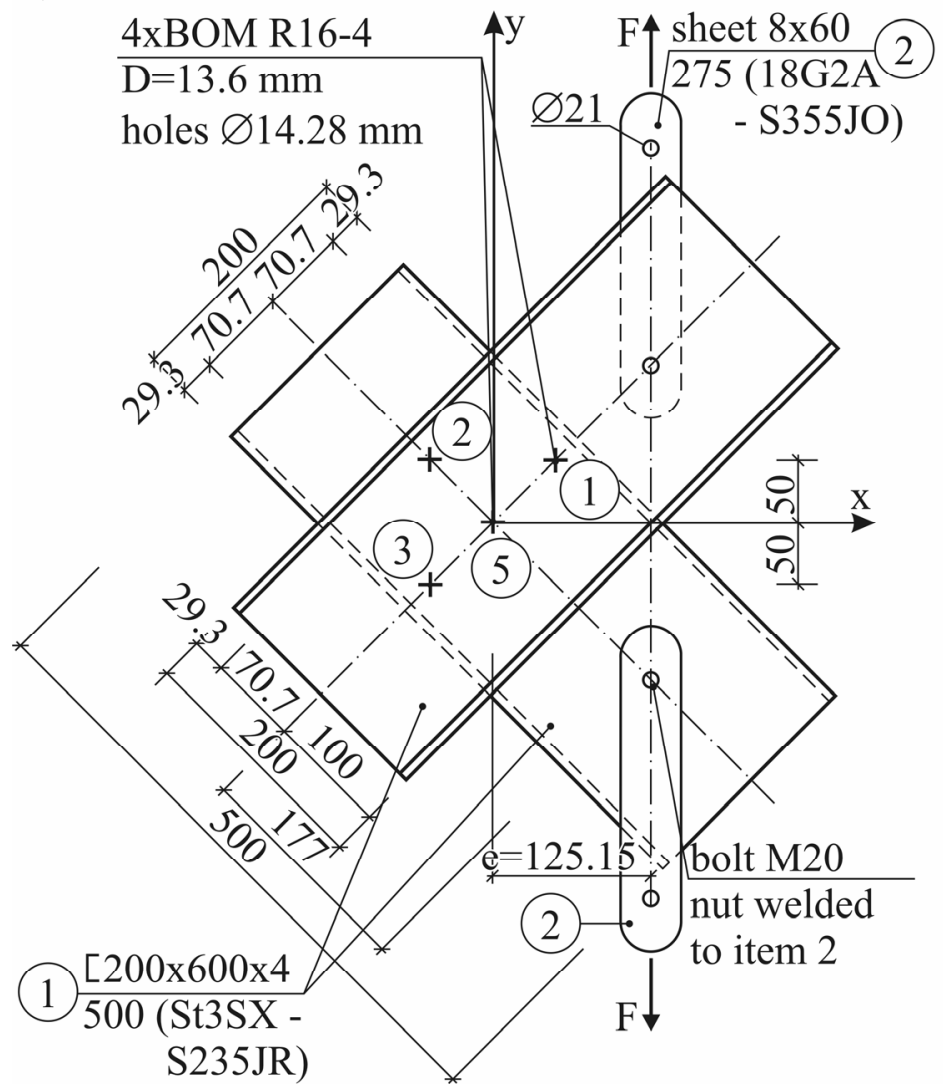

b)

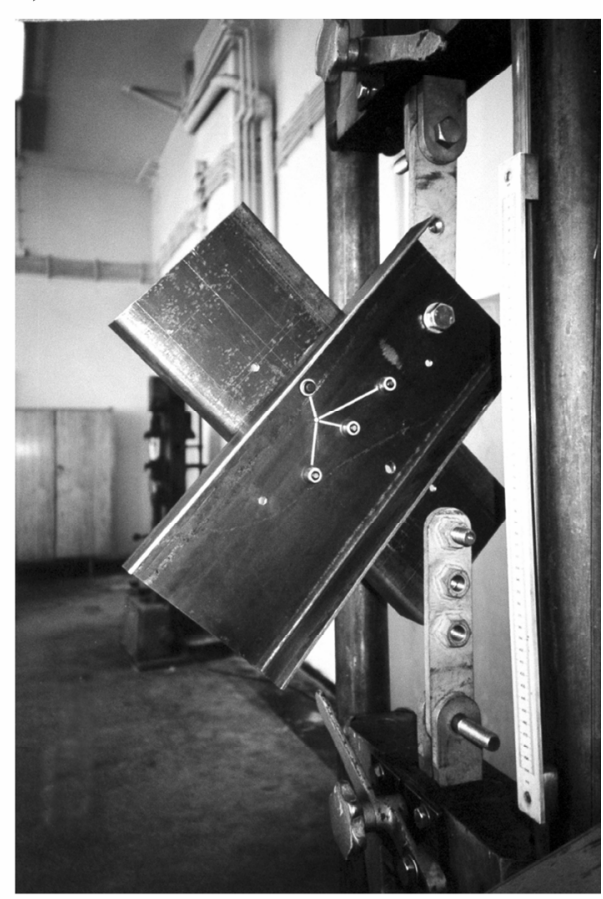

Figure 11. Test Element "V": a) Construction and Dimensions, b) Element Anchored in the Press 
Four-bolt joints were investigated in three identical test elements: V-200.4.1/4, V-200.4.2/4 and V-200.4.3/4 (Figure 11). Bolts of the type BOM R16-4 with diameters of $13.6 \mathrm{~mm}$ were placed in holes $d=14.3 \mathrm{~mm}$, drilled simultaneously in both walls, the channel bars being mutually immobilized. The joint was stretched eccentrically by the force $F$, pulsating and monotonically increasing to destruction.

The displacements were measured by means of two dial indicators, attached in the axes of the joined bent channel bars $200 \times 60 \times 4$ to the shelves - parallelly to the axes of these sections (Figure 11b). In the plan of displacements occurring in the joint (Figure 12) the average displacements of the "upper" wall $\delta_{i g}$ (the web of the "upper" channel bar) were plotted, corresponding to the $i$-th bolt, denoted in the axis of the indicator, and the axis of the bolt $\delta_{i g, c z}$ (the displacement constituted a half of the entire value $\delta_{i, s w}$ ). The radii $r_{i, R}$ connecting the instantaneous centre of rotation $R$ with axes of four bolts were denoted subsequently as $r_{1, R}, r_{2, R}, r_{3, R}$ and $r_{5, R}$.

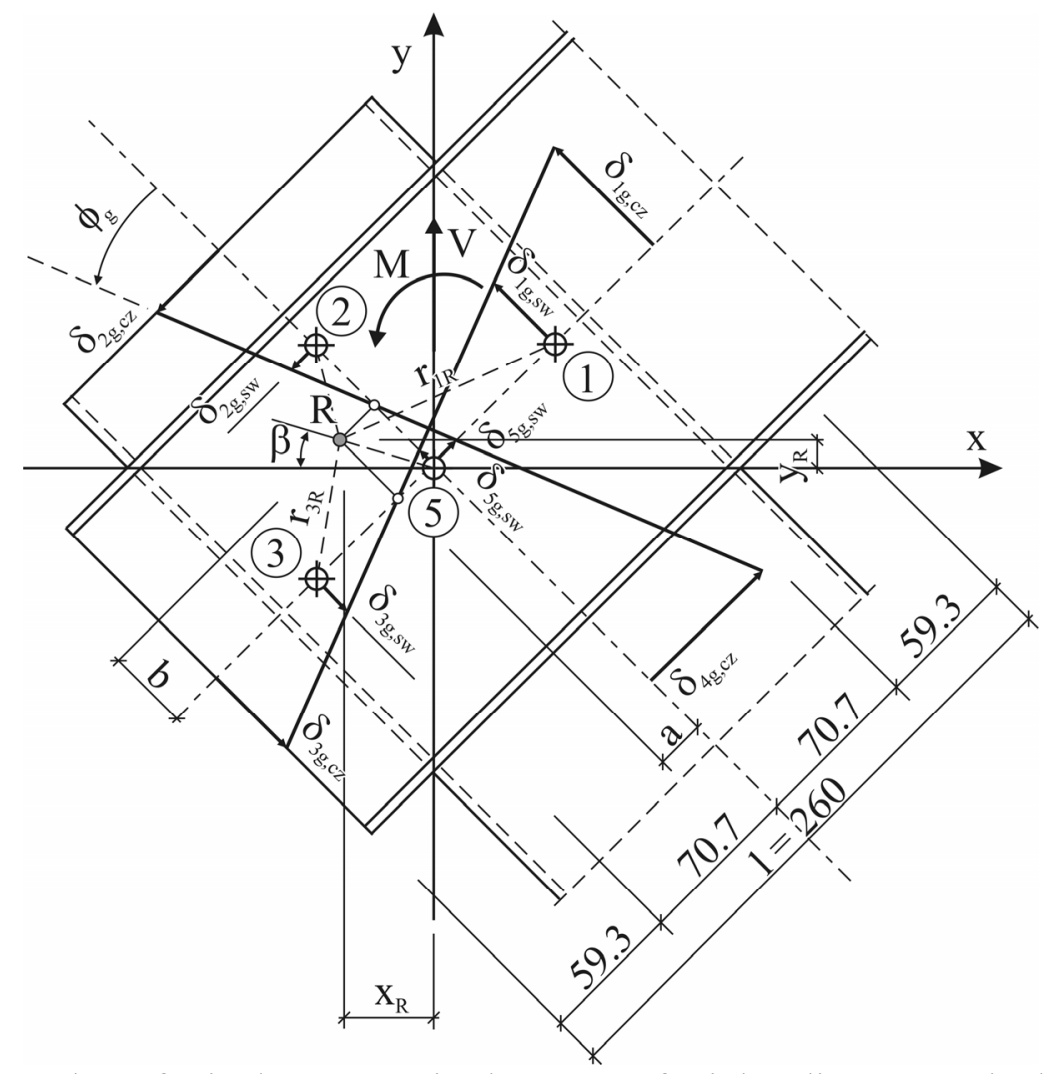

Figure 12. Plan of Displacements in the Axes of Dial Indicators and Blind Bolts in a Joint of the test element "V"

The geometrical relations in the destorted joint permitted to determine the values of the angles of rotation $\phi$ between the values of the coordinates $x_{R}$ and $y_{R}$ of the instantaneous "wandering" centre of rotation.

The behaviour of three joints is displayed by the paths of static equilibrium in the diagram $M-\phi$ (Figure 13). One of them proved to be stiffer than the other two. 


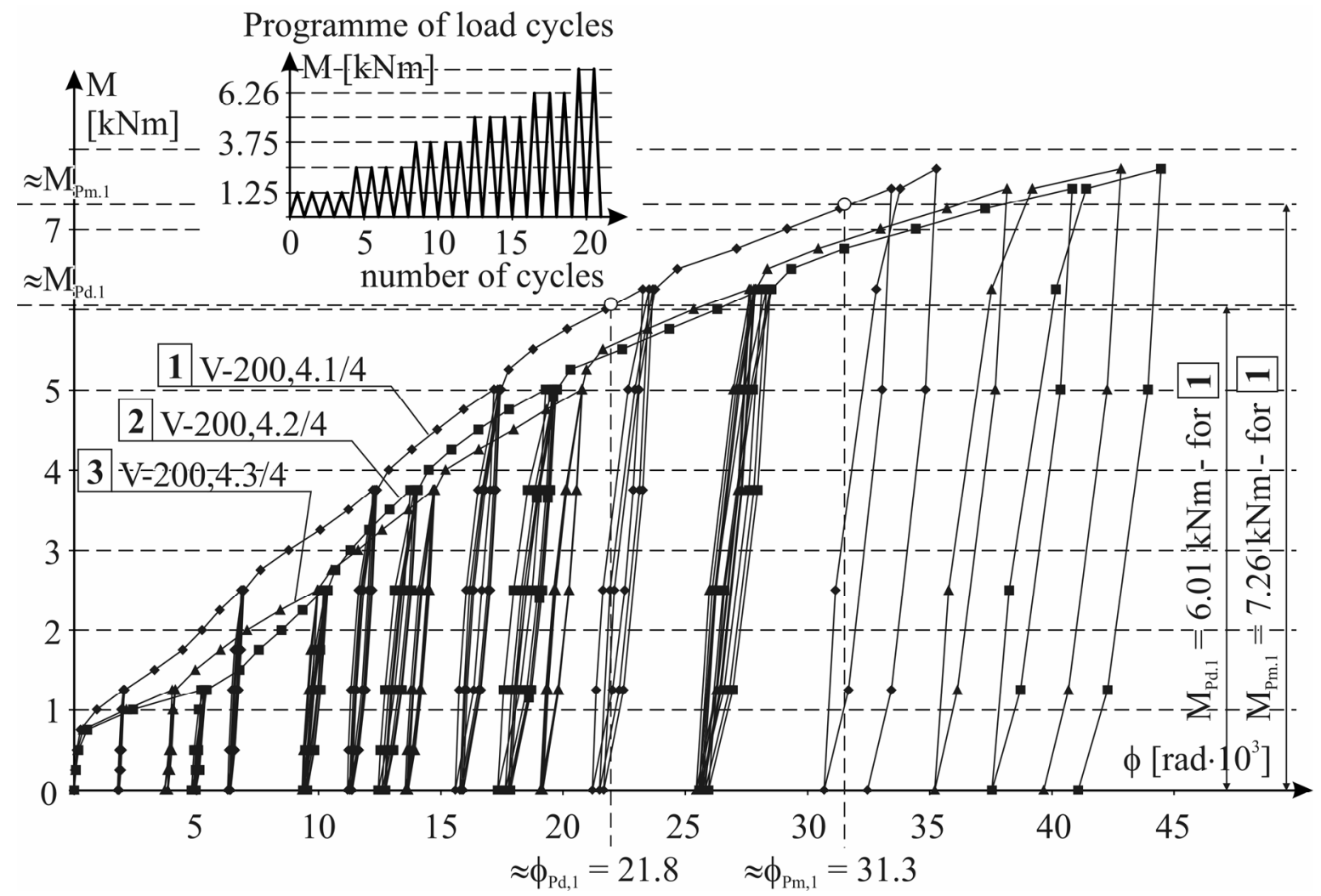

Figure 13. Paths of Static Equilibrium $M-\phi$ of a 4-bolt joint in the Test Elements:

V-200,4.1/4, V-200,4.2/4 and V-200,4.3/4

\subsection{The Set of Equations Describing the Behaviour of a 4-blind-bolt Joint}

The set of seven equations formulated in compliance with the suggestion put forward by Wuwer [1] comprises:

- three equations of equilibrium:

$$
\begin{aligned}
& H-u\left(\frac{S_{1}}{\delta_{1}}+\frac{S_{2}}{\delta_{2}}+\frac{S_{3}}{\delta_{3}}+\frac{S_{5}}{\delta_{5}}\right)+\frac{r \cdot \phi}{\sqrt{2}}\left(\frac{S_{1}}{\delta_{1}}+\frac{S_{2}}{\delta_{2}}-\frac{S_{3}}{\delta_{3}}\right)=0, \\
& V-v\left(\frac{S_{1}}{\delta_{1}}+\frac{S_{2}}{\delta_{2}}+\frac{S_{3}}{\delta_{3}}+\frac{S_{5}}{\delta_{5}}\right)-\frac{r \cdot \phi}{\sqrt{2}}\left(\frac{S_{1}}{\delta_{1}}-\frac{S_{2}}{\delta_{2}}-\frac{S_{3}}{\delta_{3}}\right)=0, \\
& \sqrt{2} \frac{M}{r}+u\left(\frac{S_{1}}{\delta_{1}}+\frac{S_{2}}{\delta_{2}}-\frac{S_{3}}{\delta_{3}}\right)-V\left(\frac{S_{1}}{\delta_{1}}-\frac{S_{2}}{\delta_{2}}-\frac{S_{3}}{\delta_{3}}\right)-\sqrt{2} \cdot r \cdot \phi\left(\frac{S_{1}}{\delta_{1}}+\frac{S_{2}}{\delta_{2}}+\frac{S_{3}}{\delta_{3}}\right)=0,
\end{aligned}
$$

- four constitutive (physical) equations, which after the introduction of the geometrical relations in the joint take the following form:

$$
\delta_{1}-\sqrt{\left[u-\frac{r \cdot \phi}{\sqrt{2}}\right]^{2}+\left[v+\frac{r \cdot \phi}{\sqrt{2}}\right]^{2}}=0,
$$




$$
\begin{aligned}
& \delta_{2}-\sqrt{\left[u-\frac{r \cdot \phi}{\sqrt{2}}\right]^{2}+\left[v-\frac{r \cdot \phi}{\sqrt{2}}\right]^{2}}=0, \\
& \delta_{3}-\sqrt{\left[u+\frac{r \cdot \phi}{\sqrt{2}}\right]^{2}+\left[v-\frac{r \cdot \phi}{\sqrt{2}}\right]^{2}}=0, \\
& \delta_{5}-\sqrt{u^{2}+v^{2}}=0 .
\end{aligned}
$$

In the Eq. $6 \div$ Eq. 9 the initial constitutive equation had the form $\delta_{i}=f\left(S_{i}\right)$ and was an anti-function to the exponential function Eq. 3. The unknown values in the set of equations are the total displacements $u, v$ and $\phi$ occurring between the joined walls and the combined forces $S_{i}$, exerted on the four bolts in the joint, i.e. $S_{1}, S_{2}, S_{3}$ and $S_{5}$.

\subsection{Comparison of Experimental and Numerical Results}

The diagram $M-\phi$ (Figure 14) provides a comparison of the three broken lines 1, 2 and 3 , corresponding to the envelope curves of the paths of equilibrium in three test elements " $\mathrm{V}$ ", with the curve 4 obtained by numerical calculations. The curve 5 was obtained making use of the programme Robot Millennium v.15 [9], which did not take into account the interactive relations, occurring in the joint between the rigidity with respect to the direction of the shearing force $V=F$ and the rotational rigidity at the bending moment $M=V \cdot e$. The investigated joints were, therefore, actually stiffer (cf. the broken lines 1,2,3) than the results of the numerical analysis (curve 4) would indicate, and more flexible, when in the calculations the interaction between two rigidities (curve 5) is neglected.

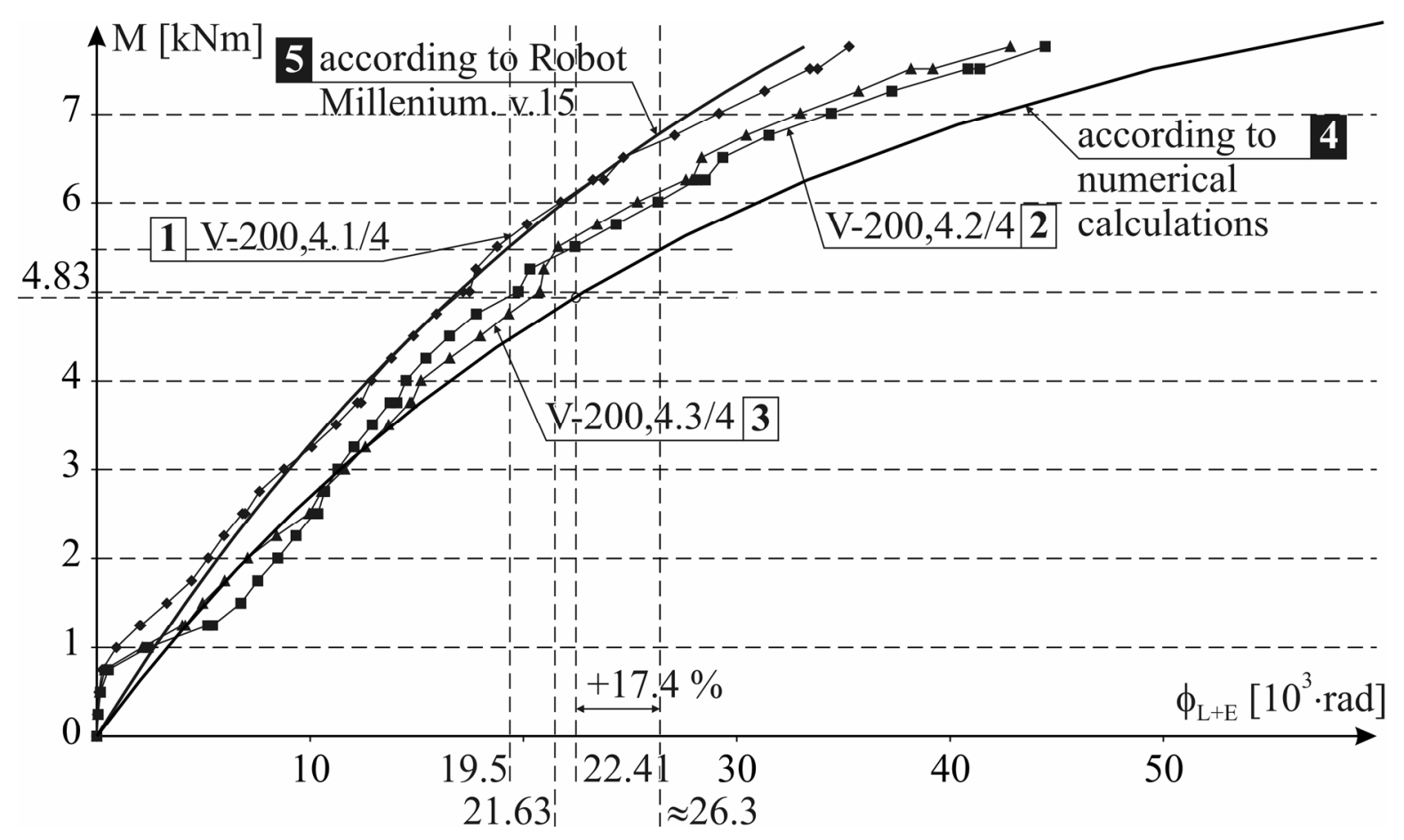

Figure 14. Relation $M-\phi$ : Broken Lines 1, 2 and 3 - for 4-blind-bolt Joints in "V" Elements; Curve 4 - According to Numerical Calculations;

Curve 5 - According to Robot Millennium v.15, [9] 
The obtained results can also be assessed by comparing in Table 1 the values of the measured coordinates of the instantaneous centre of rotation $x_{R}$ and $y_{R}$, with the values obtained as the result of numerical analysis.

Table 1. Values of the Coordinates of the Instantaneous

Centre of Rotation $x_{R}, y_{R}$ for the Joint as in Figure 12

\begin{tabular}{|c|c|c|c|c|c|c|c|c|c|c|c|c|}
\hline \multirow{2}{*}{$\begin{array}{l}\text { Loads of the } \\
\text { joints }\end{array}$} & \multicolumn{2}{|c|}{ V-200,4.1/4 } & \multicolumn{2}{|c|}{$\mathrm{V}-200,4.2 / 4$} & \multicolumn{2}{|c|}{$\mathrm{V}-200,4.3 / 4$} & \multicolumn{2}{|c|}{$\begin{array}{l}\text { mean } \\
\text { values }\end{array}$} & \multicolumn{2}{|c|}{$\begin{array}{l}\text { acc. to } \\
\text { numerical } \\
\text { calculations. }\end{array}$} & \multicolumn{2}{|c|}{ Difference in \% } \\
\hline & {$[\mathrm{mm}]$} & {$[\mathrm{mm}]$} & $\begin{array}{l}x_{R} \\
{[\mathrm{~mm}]}\end{array}$ & $\begin{array}{l}y_{R} \\
{[\mathrm{~mm}]}\end{array}$ & $\begin{array}{l}x_{R} \\
{[\mathrm{~mm}]}\end{array}$ & $\begin{array}{l}y_{R} \\
{[\mathrm{~mm}]}\end{array}$ & $\begin{array}{l}x_{R} \\
{[\mathrm{~mm}]}\end{array}$ & $\begin{array}{l}y_{R} \\
{[\mathrm{~mm}]}\end{array}$ & {$\left[\begin{array}{l}x_{R} \\
{[\mathrm{~mm}]}\end{array}\right]$} & $\begin{array}{l}y_{R} \\
{[\mathrm{~mm}]}\end{array}$ & $\begin{array}{l}{[(9) /(11)} \\
-1] \cdot 100\end{array}$ & $\begin{array}{l}{[(10) /(12)} \\
-1] \cdot 100\end{array}$ \\
\hline 2 & 3 & 4 & 5 & 6 & 7 & 8 & 9 & 10 & 11 & 12 & 13 & 14 \\
\hline 0.0 & 0.0 & 0.0 & 0.0 & 0.0 & 0.0 & 0.0 & 0.0 & 0.0 & 0.0 & 0.0 & 0.0 & 0.0 \\
\hline 1.252 & -42.6 & 11.2 & -46.8 & 8.5 & -34.5 & 11.4 & -41.3 & 10.4 & -37.7 & 12.4 & 9.6 & -16. \\
\hline 2.504 & -36.9 & 10.7 & -42.4 & 13.0 & -36.5 & 5.6 & -38.6 & 9.8 & -38.0 & 12.2 & 1.6 & -19. \\
\hline 3.756 & -33.1 & 10.3 & -39.9 & 13.4 & -37.4 & 8.7 & -36.8 & 10.8 & -38.3 & 12.1 & -3.9 & -10.7 \\
\hline 5.008 & -34 & 10.9 & -39 & 12.5 & -37 & 10.7 & & & -38.6 & 11.9 & -3.9 & -4.2 \\
\hline 6.260 & -35.7 & 11.3 & -39.9 & 12.9 & -37.9 & 11.4 & -3 & & -39 & & -3.1 & \\
\hline 7.512 & -37.5 & 12.3 & -40.3 & 12.8 & -38.4 & 13.0 & -38.7 & 12.7 & -39.4 & 11.8 & -1.8 & 7.6 \\
\hline 7.762 & $-37,8$ & 12,3 & -40.4 & 12.5 & -38.9 & 13.3 & -39.0 & 12.7 & -39.5 & 11.8 & -1.3 & 7.6 \\
\hline
\end{tabular}

\subsection{Reasons of the Differences between Experimental and Theoretical Results}

The scatter of results in bent and sheared 4-blind-bolt joints, which neither in their character nor in their quantity deviate from those occurring in stretched 2-blind-bolt joints (cf. Figures. 8 and 13). The scatter of results may be due to:

a) the technique of embedding the bolts in the holes,

b) the accuracy of drilling in the joined walls,

c) the fatigue of the material of the wall in the borehole, caused by the low-cyclic loading exerted by the side surface of the bolt mandrel,

d) the forces of sliding friction in the stretched joint,

e) the forces of .journal friction in a simultaneously stretched and bent joint.

The reason for which the producer permits to embed bolts with a diameter of $13.6 \mathrm{~mm}$ in boreholes, the diameters of which are contained in the range of $13.3 \div 14.8 \mathrm{~mm}$, may be accounted for by the differentiated flexibility of the joints, but - as has turned out - this is not the most important reason. The accuracy of drilling all the bore-holes separately in the individual walls of the elements "I" by hand may affect to some extent the filling of the holes with the material of the blind bolt sleeve, although not essentially, because in the case of "V" elements in which the holes were drilled and the bolts were embedded in immobilized sections the values were still scattered.

Presumably the fatigue of the material in the vicinity of the bolts may also have influenced the variety of results. The crystalline structure of steel in the pressed wall of the hole may have undergone changes caused by the reiterated cyclic loading with the forces $S_{i}$, the stresses in the wall considerably having exceeded the yield point. In the loaded wall may - according to Dietrich [7] have started the development of the slipping line and cracking.

It is characteristic that displacements $\delta_{L+E}$ between the joined walls are not repeated in the case of stretched 2-blind-bolt joints in elements of type "I" during the initial phases of loading, when the first displacements are "released" (Figure 15). The mutual displacement of joined walls is connected with the mastering of some forces of sliding friction caused by rather small tensile forces in the mandrels of the bolts, remaining in them after having been embedded in the holes. 


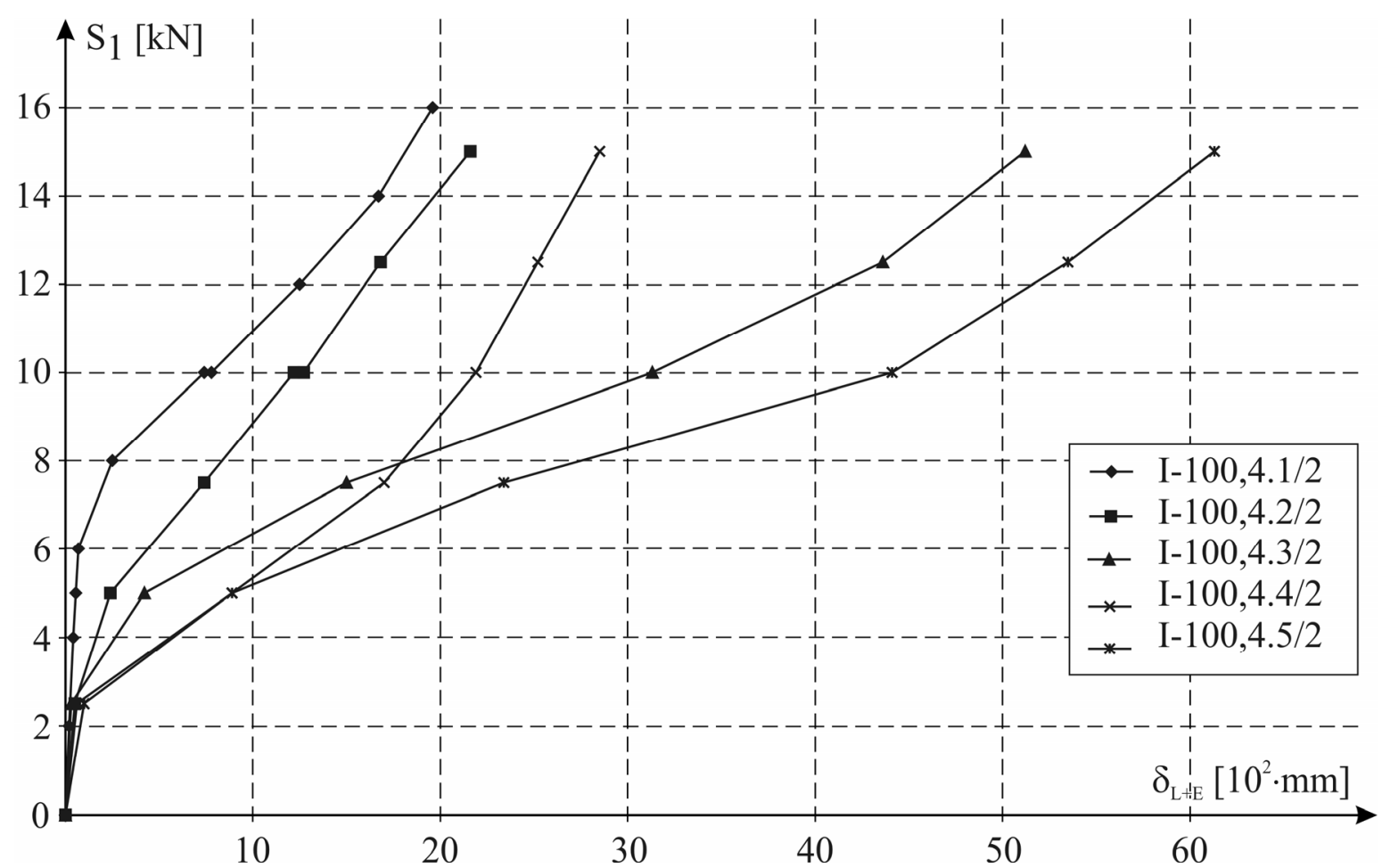

Figure 15. Displacements during the Initial Phases of the Torsion of 2-blind-bolt Joints in Five Test Elements "I"

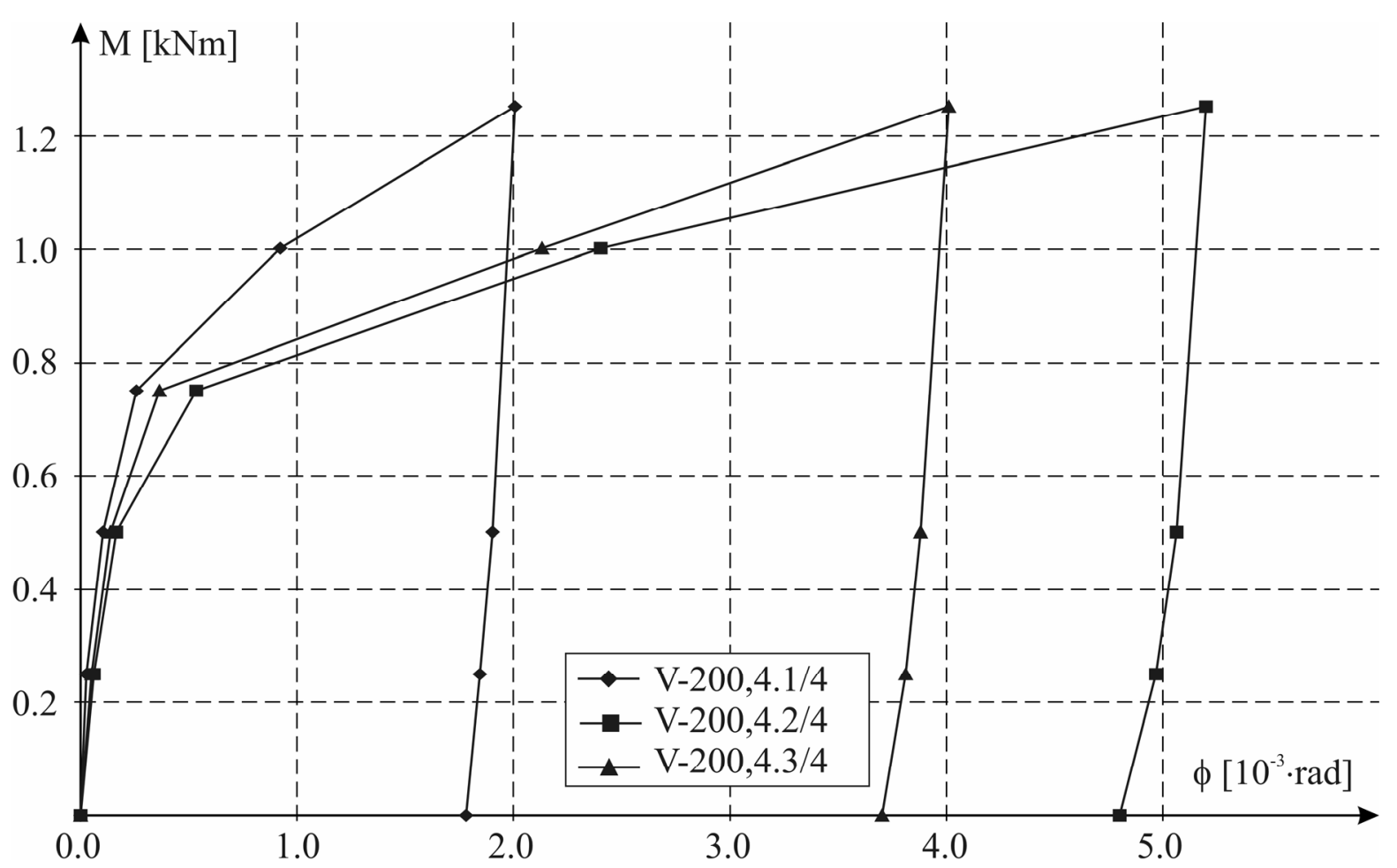

Figure 16. Relation $M-\phi$ in the Initial Increments of Load in "V"-type Joints

Similar differences have been observed in angular displacements occurring in simultaneously sheared and bent walls (Figure 16). The relaxation and creeping, as well as the degradation of rigidity in the case of greater loads, were doubtlessly indications of a local fatigue of the material; durable displacements, which in the case of $S_{i}>P_{d}$, increased successively and did not stabilize after several iterations, as has been the case earlier, may also serve as a prove of this phenomenon. 
A certain role may also be played by the forces of sliding and journal friction. The former ones have been taken into account in the set of Eq. $3 \div$ Eq. 9, the latter, however, have been neglected. In a joint transferring the loads $M, H$ and $V$, in the axis of the $i$-th blind bolt a torque moment $M_{i, \phi}$, occurs counteracting the mutual torque of the joined walls by the angle $\phi$ (Figure 17). In a joint with $\mathrm{m}$ links the mutual torque of the walls by the angle $\phi=\phi_{g}+\phi_{d}$ (cf. Figure 12) is counteracted by the sum of torque moments $\sum M_{i, \phi}$, which may cause a certain reduction of angular displacement $\phi$.

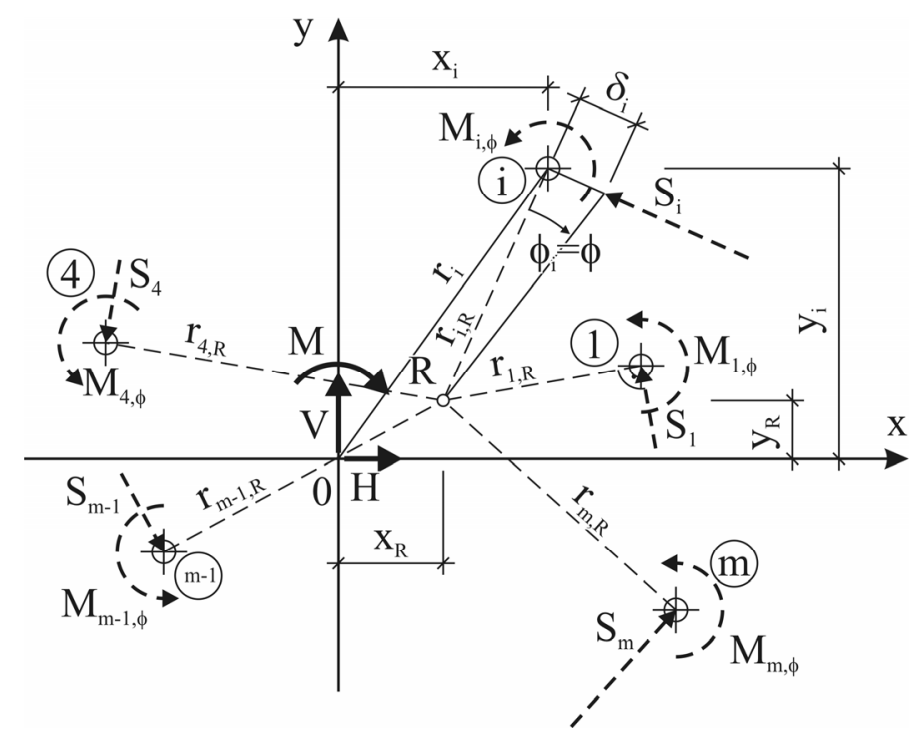

Figure 17. Diagram of the Interactions $S_{i}$ of the "Bottom" Disk with

Torque Moments $M_{i, \phi}$ during the Transfer of the Loads $H, V$ and $M$ from the "Upper" Disk

The value of the $i$-th torque moment $M_{i, \phi}$, depending on the load $S_{i}$, shearing the bolt "i", consists of journal friction forces existing between (Figure 18):

- the blind bolt heads and the external surfaces of the joined walls,

- the cylindrical side surface of the blind bolt and the wall in the hole,

- the adjacent internal surfaces of the joined walls, brought about by the tilt of the blind bolt inside the hole.

The increasing forces $S_{i}$ accompanied by a simultaneous tilting of the bolts in the holes may have caused an increase of rigidity of the 4-blind-bolt joint.

\subsection{Boundary Curves of a 4-Blind-bolt Joint}

In the investigated joints three variants of boundary states were tested in a dimensionless set of rectangular coordinates $M / M_{\lim }^{I I I}$ and $V / V_{\lim }^{I I I}$. Variant I concerns the situation when at least one link in the joint is loaded with a force equal to the calculated load-carrying capacity $P_{d}$, the variant II - when the mutual linear displacement of the joined walls attains at the point with the most intensive effort the boundary the value $\delta_{\text {lim }}=3.0 \mathrm{~mm}$, and variant III corresponds to the theoretical boundary state of destruction of the joint, when the loads of all joints attain boundary values. 


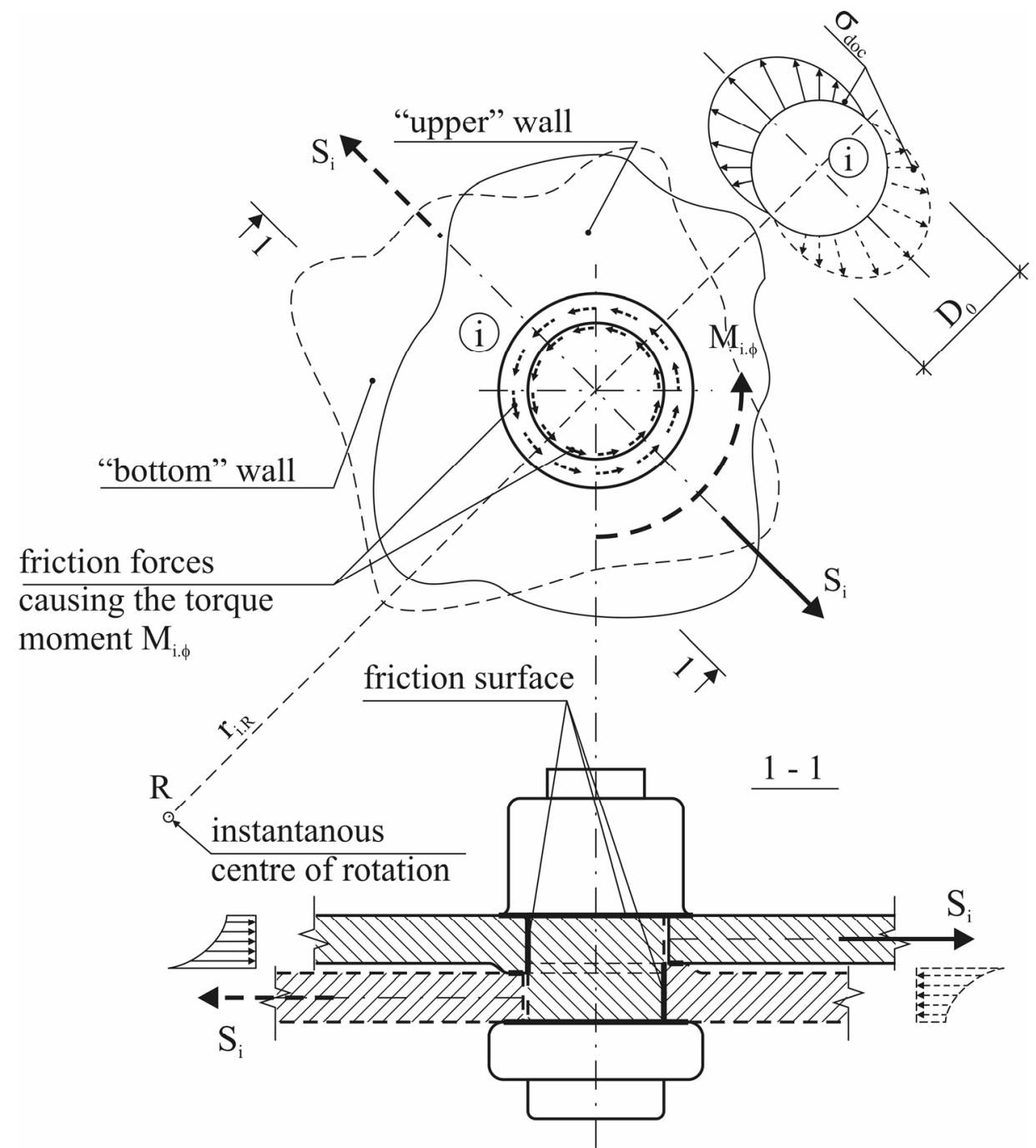

Figure 18. Friction Forces in the Axis of the Bolt "i" in a Lap Joint Loaded with the Bending Moment $M$ and Shearing Forces $H$ and $V$

The set of Eq. $3 \div$ Eq. 9 ought to satisfy the following conditions concerning the joint "i" with the most intensive effort:

- in the case of boundary state I - with respect to the calculated load-carrying capacity of the joint

$S_{i, \max } \leq S_{\text {lim }}^{\mathrm{I}}=P_{d}$

- in the case of boundary state II - with respect to boundary displacements of the joined walls

$\delta_{i, \max }=f\left(S_{i}\right) \leq \delta_{\lim }=3.0 \mathrm{~mm}$,

when $S_{i, \max } \leq S_{\text {lim }}^{\mathrm{II}}=P_{m, \text { med }}$,

- in the case of boundary state III - with respect to the theoretical destruction of the joint

$S_{i, \max } \leq S_{\lim }^{\mathrm{III}}=P_{\text {destr }}$. 
Basing on results obtained in some other tested joints, also internally statically indeterminable, it was acknowledged that the compatibility of experimental and numerical results is satisfying and the model of calculations is correct. The quoted set of equations could, therefore, be used to plot boundary curves separately for each of the four joints in the system of dimensionless rectangular coordinates $M / M_{\lim }^{I I I}$ and $V / V_{\lim }^{I I I}(H=0)$.

In numerical calculations the load $V$ was exerted on the joint at the eccentricities $e$, both the positive and the negative one (cf. Figure 11a). The diagram in Figure 19, for instance, illustrates the areas, enclosed by the boundary curves I, II and III, respectively, for the boundary loads $S_{1, \lim }^{I}$, $S_{1, \lim }^{I I}$ and $S_{1, \lim }^{I I}$, i.e. for the bolt No. 1 (cf. Figure 1c).

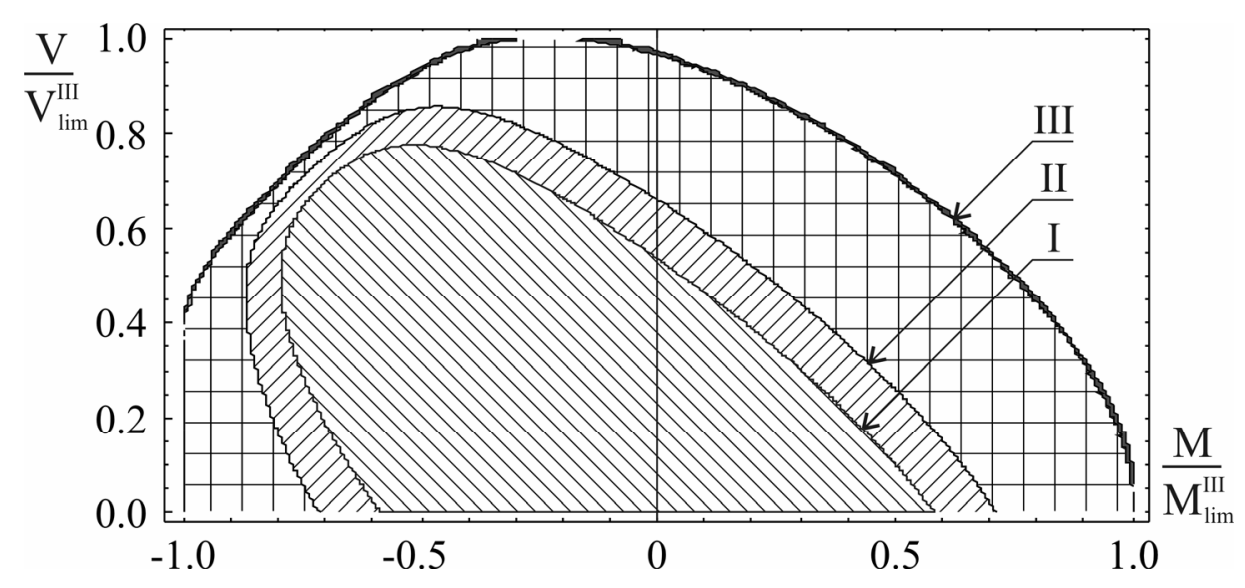

Figure 19. Areas Enclosed by Three Boundary Curves I, II and III of the Force Si for the Bolt No. 1 in the Joint, as in Figure 1c, [4]

The boundary curves for the four bolts in the joint, corresponding to the boundary state I, ware plotted in a common diagram (Figure 20). The surface enclosed by the boundary curves $S_{1}$ and $S_{2}$, below their point of intersection at the height of the abscissa $V / V_{\text {lim }}^{I I I}=1.0$, determines the area corresponding to the calculated load-carrying capacity of the joint.

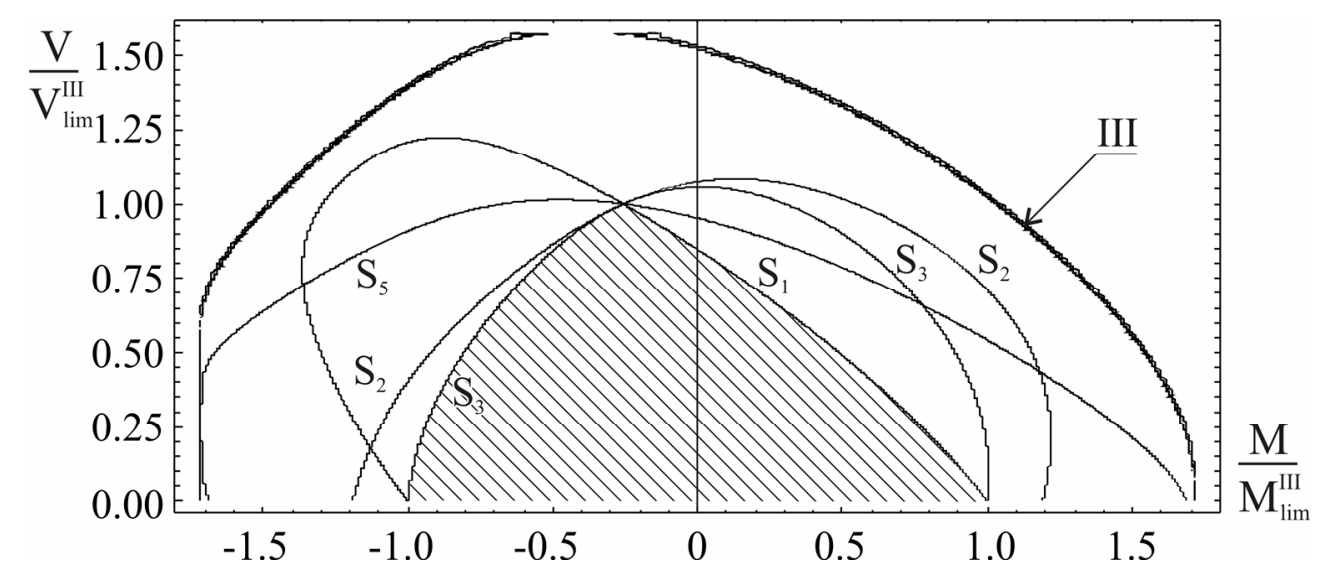

Figure 20. Boundary Curves of the Forces $S_{1}, S_{2}, S_{3}$ and $S_{5}$ of the Case of the Boundary State I,

Respectively for the Bolts No. 1, 2, 3 and 5 in the Joint Presented in Figure 1c, and the Boundary Curve III (Boundary of the Mathematical Model), [4] 


\section{DESIGN OF A FRAME WITH FLEXIBLE NODES}

\subsection{Assumptions and Fundamentals of Calculation}

Basing on the example of a frame designed by Wuwer and Kowolik [8] of sheet-metal sections with closed and open cross-sections and eccentrically joined bars in the nodes, the effect of the instantaneous rigidity of the joints on the static behaviour of the frame was assessed (Figure 21). The walls of sections $5.0 \mathrm{~mm}$ thick (of steel S235 JR) were joined in the nodes by blind bolts of the type BOM R16-6, class 12.9. The values of single-cut 5-blind-bolt joints change non-linearly due to the ovalization of the holes (approved by the standard [10]), affecting a plastic failure of the walls in the holes, propagating with the increase of the axial forces $V$, the transverse forces $H$ and the bending moment $M$. The way of calculating a multi-blind-bolt lap-joint was presented by Wuwer [1, 2].

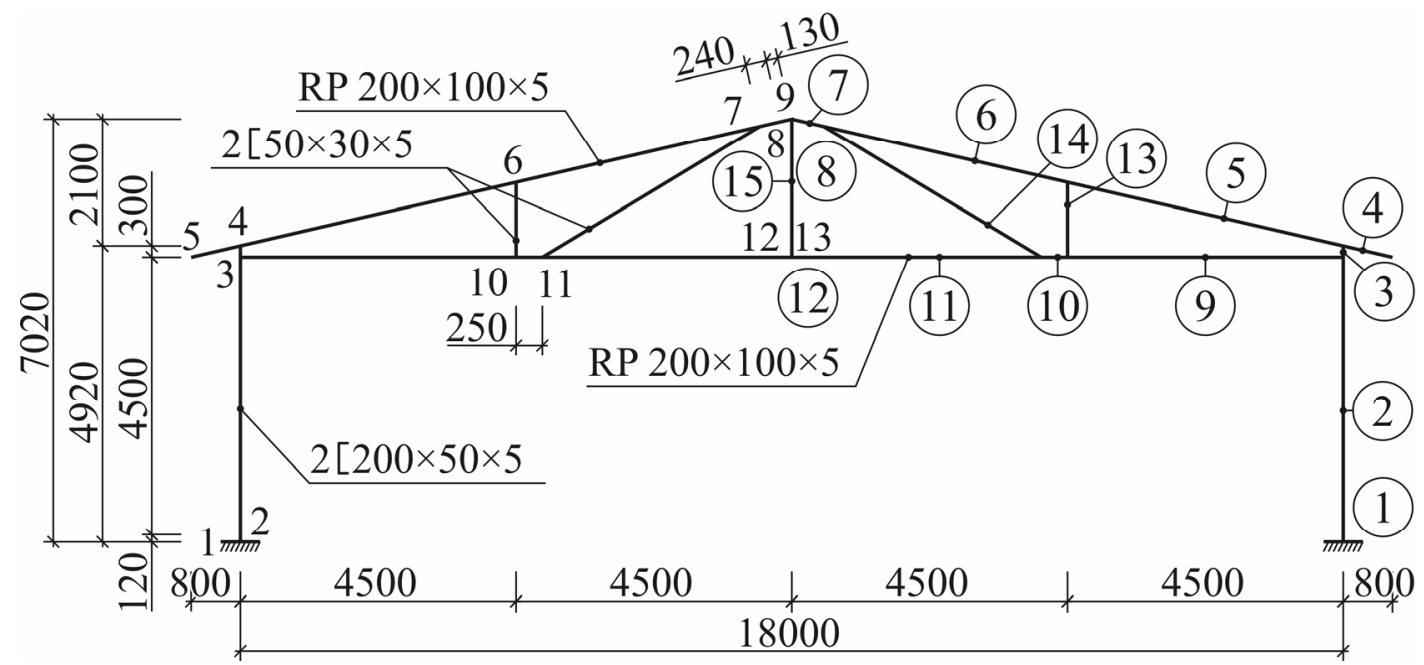

Figure 21. Diagram of a Frame with the Cross-sections of the Bars and the Numeration of the Bars and Nodes

Up to now the authors of the paper Wuwer and Kowolik [11] have carried out static calculations of a lattice frame with a span of $20.0 \mathrm{~m}$ and nodes constructed using the same joints, introducing values of the secant rigidity and strain rigidity, instead of the an instantaneous rigidity. The influence of interactive dependences occurring in the nodes of the frame between the values of the three rigidities which go together with the loads $V, H$ and $M$, respectively, was there neglected. This influence was taken into account in calculations concerning the frame presented in Figure 21, applying formulae quoted by Wuwer [2], describing the nonlinearly changing values of the rigidity of the joints by means of three reductive coefficient of rigidities; the coefficient $v_{M}$ reduced the value of the rotating rigidity combined with the bending moment $M$ in result of the simultaneous shearing of the joints by the two other forces $V$ and $H$; whereas the reductive coefficients $v_{V}$ and $v_{H}$ reduce the rigidity in the direction of the forces $V$ or $H$, respectively, due to the jointly acting forces $M$ and $H$ or $M$ and $V$. The values of the reductive coefficients were taken from contour lines constructed by solving a set of eight equations describing the static behaviour of a 5-blind-bolt joint, Wuwer [2]. The developed contour lines of three coefficients of the reductive rigidity were presented by Wuwer and Walentynski [5]. The contour lines were plotted on diagrams of dimensionless rectangular co-ordinates $M / M_{\lim }$ and $W / W_{\lim }$, concerning cases in which the directions of inclination of the resultant force $W$, the components of which are the forces $H$ and $V$, change every $15^{\circ}$. In each node of the frame presented in Figure 1 single-cut joints were assumed, either as 5-blind-bolt joints or single-blind-bolt joints. Calculations concerning this frame were carried out by applying the programme Robot Millennium v.15 [9], making use of the option of nonlinear releases of the bars. 


\subsection{Load-carrying Capacity of a 5-Blind-bolt Joint}

Single-cut lap-joints of the upper and the bottom flange (RP $200 \times 100 \times 5)$ in the nodes 8 and 12, i.e. in the vicinity of the roof ridge joints, connecting the columns $(2[200 \times 50 \times 5)$ subsequently with the anchoring elements at the bottom and the bottom and upper flanges (cf. Figure 21), were constructed by means of 10 bolts, 5 in each joint connecting two adjacent walls of the sections (Figure 22).

a)

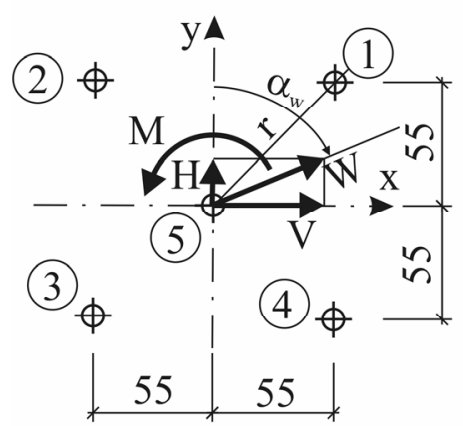

b)

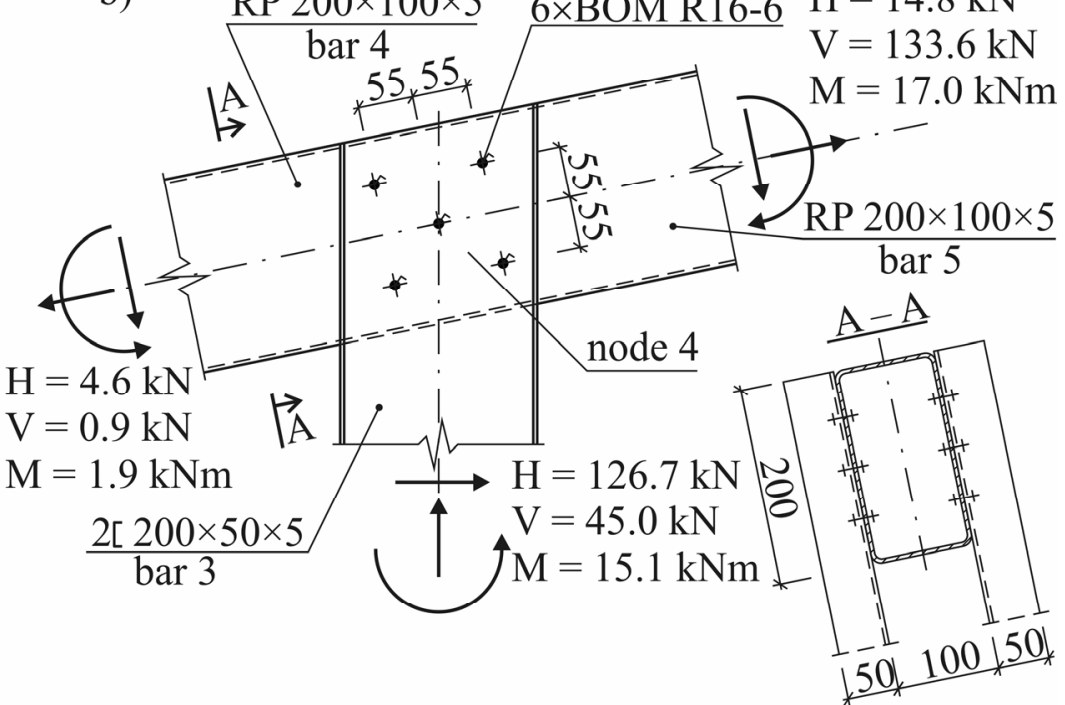

Figure 22. Assumptions for Calculations: a) Draft of a 5-Blind-bolt Joint bent by the Momentum M and Sheared by the Force W inclined Versus the Axis y at the Angle $\alpha_{W}$,

b) Construction of the Quoin of the Frame in the Node 4 and the Loads $M, H$ and $V$ of the Bars, According to the Final Results of Calculations (cf. Column 5 in Table 2)

The number of bolts assumed in the calculations was not rational, because in some joints the load-carrying capacity was not taken into account. In the dimensioning of the joints already existing diagrams of the boundary curves were used, as well as the contour lines of the reduction coefficients, developed so far only for a 5-blind-bolt joint (cf. Figure 22a). Double-branch bars 13 and $14(2[50 \times 30 \times 5)$ were joined with the flanges in an articulated way, i.e. by two joints in each node $6,10,7$ and 11 .

Calculations concerning a 5-blind-bolt joint were carried out by solving a set of equations, consisting of three equations and geometrical relations and a constitutive equation, providing five equations, Wuwer [1]. The constitutive equation had the form of a function reciprocal to the relation $S_{1}-\delta_{L+E}$, connecting the load $S_{1}$ of a single bolt with the mutual displacement $\delta_{L+E}$ of the joined walls, in compliance with the relation (2) (cf. Figure 10, curve II).

The numerical solution of this set of equations provided results expressed by the values of the forces $S_{i}$ exerted on the individual joints and of the displacements $\delta_{i}$ between the joined walls of the sections, where " $i$ " denotes the subsequent joints numbered $1 \div 5$ (cf. Figure $22 \mathrm{a}$ ) in the considered joint.

The values of the forces $S_{i}$ and the displacements $\delta_{i}$ were compared on contour lines with the boundary values, Wuwer and Walentynski [5]. As examples of the behaviour of the bolts 1 and 2 (cf. Figure 22a) may serve the contours of the forces $S_{1}$ and $S_{2}$ (Figure 23) and the corresponding contours of displacements $\delta_{1}$ and $\delta_{2}$ (Figure 24). The contours corresponding to the calculated load-carrying capacity $S_{1}=S_{2}=P_{d}=48.6 \mathrm{kN}$ (in the case of the boundary state I) and the boundary 
load-carrying capacity $S_{1}=S_{2}=P_{m}=55.85 \mathrm{kN}$, as well as the contours corresponding to the displacements $\delta_{L+E, d}=209.3 \cdot 10^{-2} \mathrm{~mm}$ and $\delta_{\text {lim }}=3.0 \mathrm{~mm}$ (the case of the boundary state II) have been singled out in the diagrams.

a)

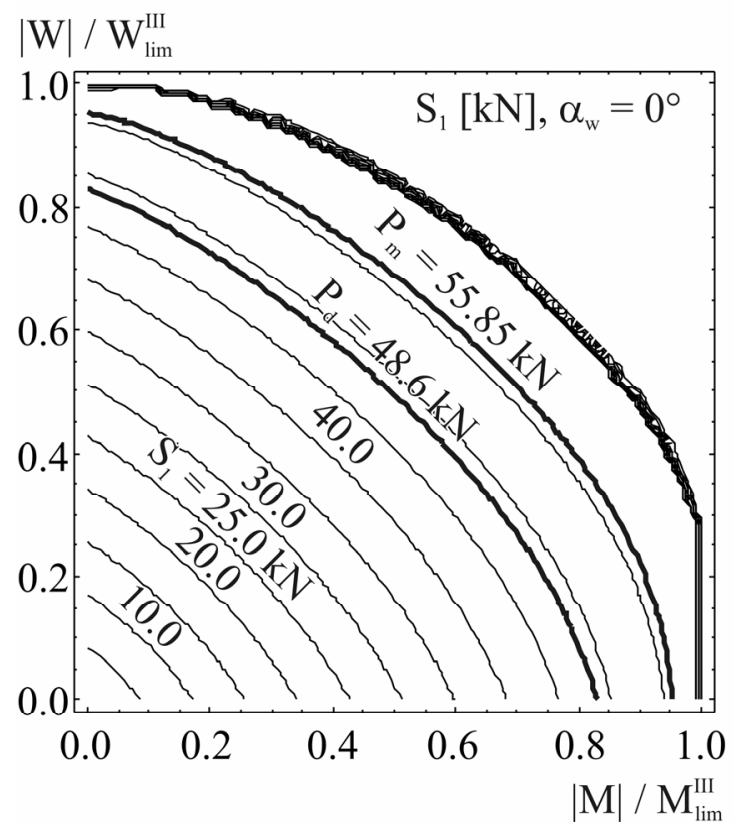

b)

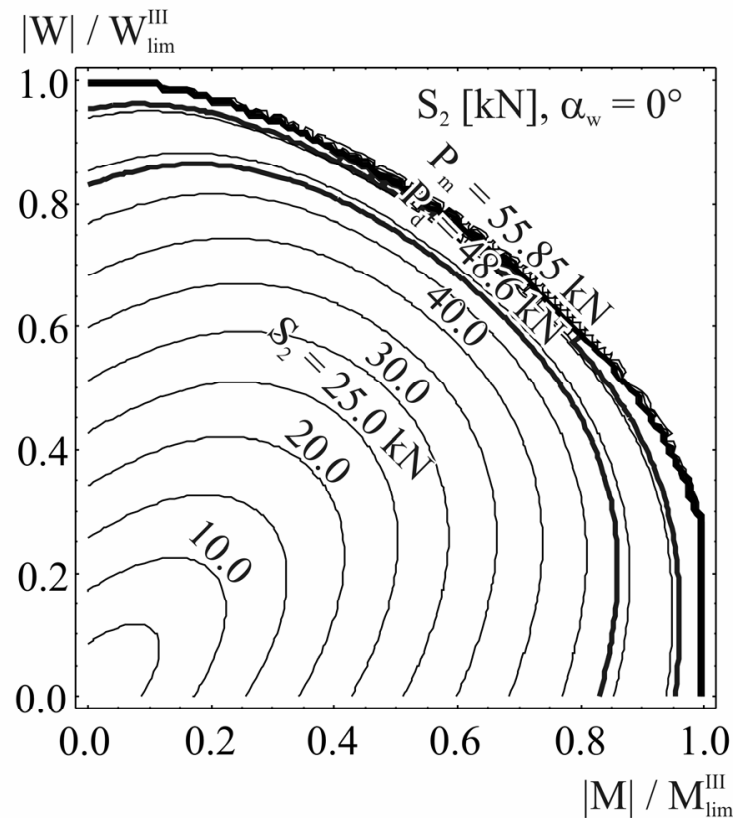

Figure 23. Contour Lines of the Forces $S_{1}$ and $S_{2}$ Exerted in a 5-Blind-bolt Joint on a) the Bolt No.1, b) Bold No.2, Respectively, [5]

a)

$|\mathrm{W}| / \mathrm{W}_{\text {lim }}^{\mathrm{III}}$

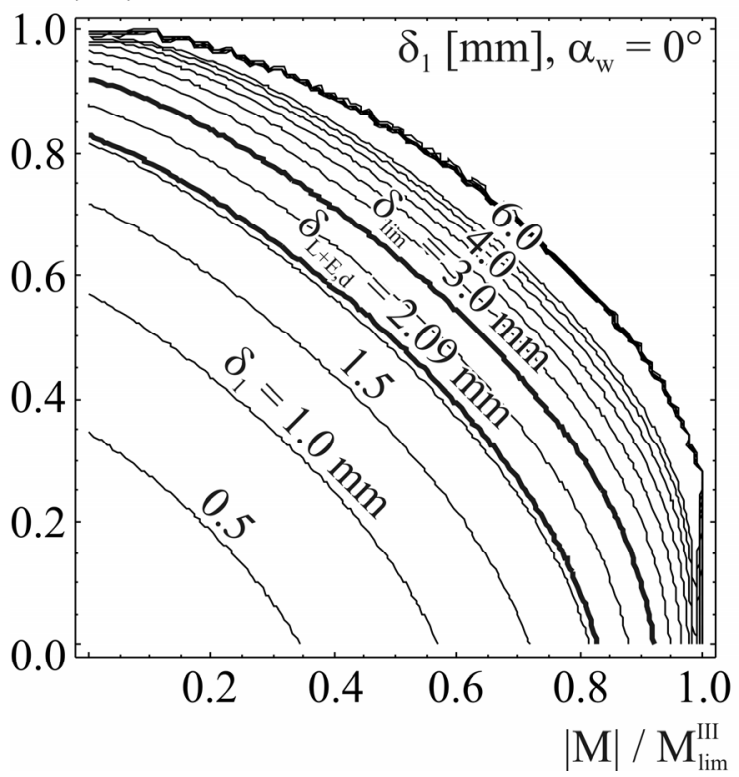

b)

$|\mathrm{W}| / \mathrm{W}_{\mathrm{lim}}^{\mathrm{III}}$

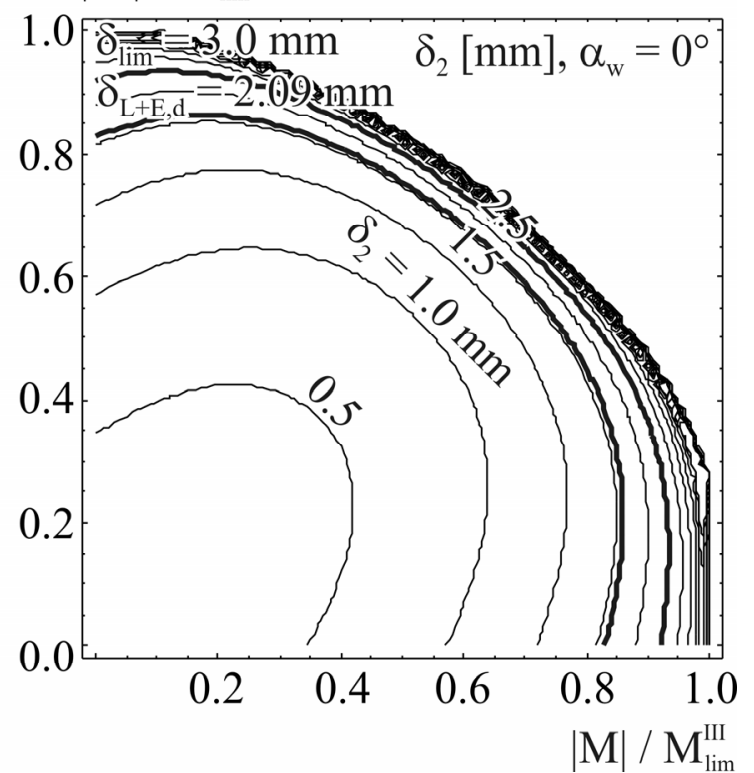

Figure 24. Contour Lines of the Displacements $\delta_{1}$ and $\delta_{2}$ Occurring

Between the Joined Walls in a 5 Blind-bolt Joint in the Case of a) Bolt No. 2, b) Bolt No. 2, [5]

Concerning the behaviour of joints three cases of the boundary states were considered in the dimensionless rectangular coordinate system $M / M_{\text {lim }}^{I I I}$ and $W / W_{\text {lim }}^{I I I}$. The first case concerns the situation when at least one link in the joint is loaded with a force equal to its calculated load-carrying capacity $P_{d}$, and the second case the situation when the mutual linear displacement of 
the joined walls achieves in the place of the: highest effort the boundary value $\delta_{\text {lim }}=3.0 \mathrm{~mm}$. The third case corresponds to the theoretical boundary state of destruction of the joint, i.e. when the loads on all the joints reach boundary values. The shapes of all the three boundary curves change with the angle of inclination of the resultant force $W$ in the joint, as is to be seen in Figure 25, corresponding to the case when $\alpha_{W}=0$ or $\pi / 2$ and $\alpha_{W}=\pi / 4$.
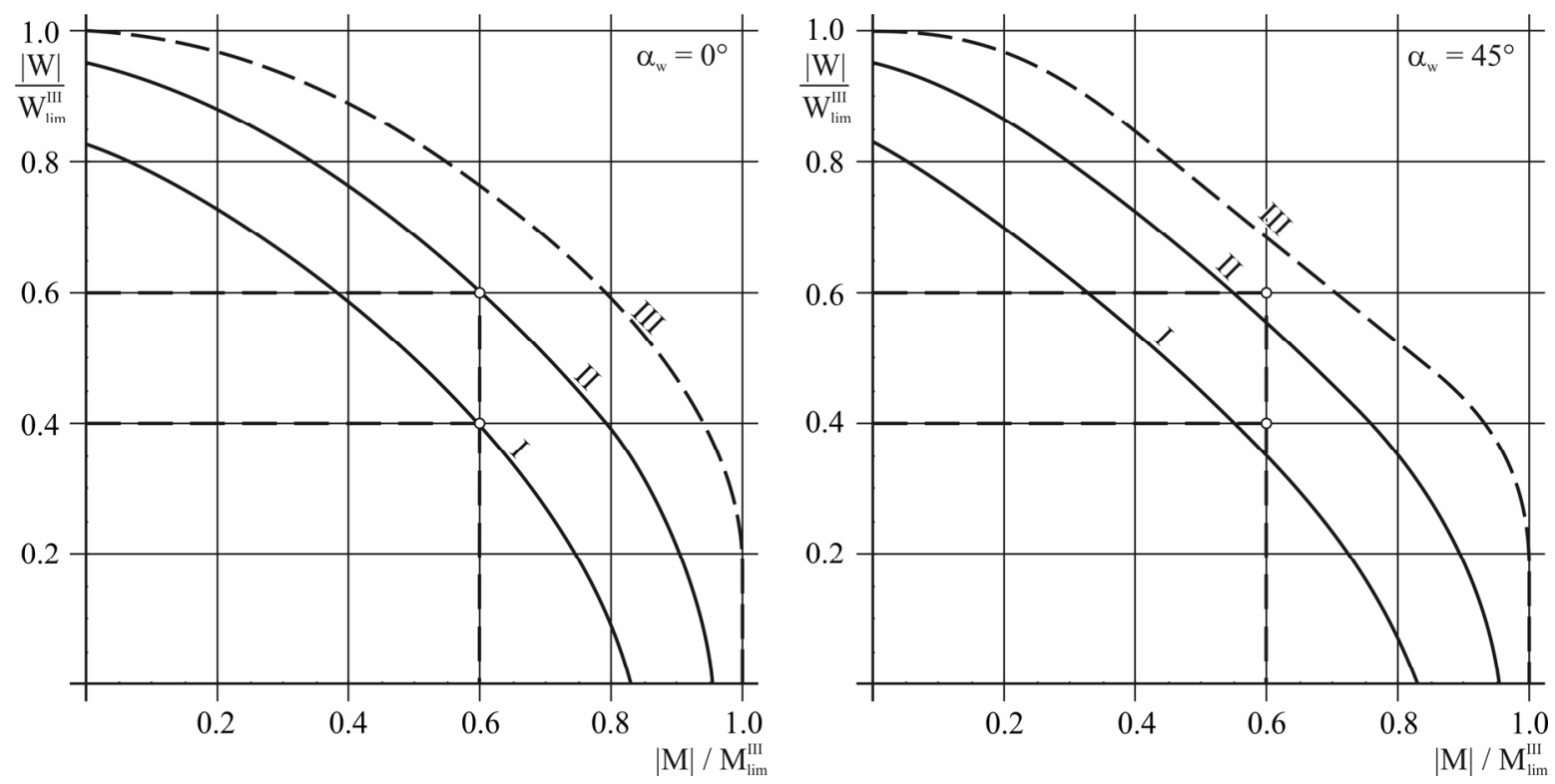

Figure 25. Boundary Curves of the Load-carrying Capacities I, II and III of a 5-Blind-bolt joint Loaded with the Forces $M$ and $W$ Concerning Two Different Loads:

a) When $\alpha_{W}=0$ or $\pi / 2$, b) When $\alpha_{W}=\pi / 4$, [5]

The diagrams plotted basing on the results of numerical analyses indicated, for instance, that in the case of the load $M$ and $W$, when $W / W_{\text {lim }}^{I I I}=0.4$ and $M / M_{\text {lim }}^{I I I}=0.6$, the condition of the calculated load carrying capacity of a 5-blind-bolt joint is maintained at $\alpha_{W}=0$ or $\pi / 2$, but at the same values of the load $M$ and $W$ it is exceeded already when $W / W_{\lim }^{I I I}=M / M_{\lim }^{I I I}=0.6$. Boundary curves I considerably felicitated the checking of the calculated load carrying capacity of the joints in the nodes numbered 2, 3, 4, 8 and 12 .

\subsection{Rigidity of a 5-Blind-bolt Joint}

The rigidity of joints was calculated basing on the Eq. 2, which permits to express the rigidity of a single bolt in the joint by the equation Wuwer [1]:

$K_{r t}^{S}=\frac{d S_{1}}{d \delta}=a_{S} \cdot b_{S} \cdot e^{-b_{s} \cdot \delta_{L+E}}$,

but the values of three instantaneous rigidities associated with the forces $V, H, M$ are calculated by means of the formulae:

$$
\begin{aligned}
& K_{r t}^{V}=m \cdot K_{r i}^{S} \cdot\left(1-\omega_{V}\right) \cdot v_{V}, \\
& K_{r t}^{H}=m \cdot K_{r i}^{S} \cdot\left(1-\omega_{H}\right) \cdot v_{H}, \\
& K_{r t}^{M}=(m-1) \cdot r^{2} \cdot K_{r i}^{S} \cdot\left(1-\omega_{M}\right) \cdot v_{M} .
\end{aligned}
$$


As there are two 5-blind-bolt joints in the nodes 2, 3, 4, 8 and 12, the values of rigidity calculated according to Eq. 13, Eq. 14 and Eq. 15 were taken in the calculations as twice as high. In order to simplify the calculations it has been assumed that in each joint the load consists of the bending moment $M$ and only one shearing force $W$, which always equals the larger force of the two component loads $V$ and $H$, i.e. which is parallel either to the axis $y$ or $x$ of the coordinate system; thus, for $\alpha_{W}=0$ or $\alpha_{W}=\pi / 2$, respectively (cf. Figure 22b).

The reduction coefficients $v_{M}$ and $v_{W}$, were taken from the contour lines plotted in the diagrams as a system of non-dimensional quantities $W / W_{\lim }^{I I I}$ and $M / M_{\text {lim }}^{I I I}$. Figure 26 presents the contours of the coefficients $v_{M}^{I I I}$ and $v_{W}^{I I I}$ plotted in a common diagram versus the third boundary state with the boundary values of the load amounting to $W_{\lim }^{I I I}=5 \cdot S_{\lim }^{I I I}=$

$5 \cdot 58.58 \mathrm{kN}=292.9 \mathrm{kN}$ and $M_{\mathrm{lim}}^{I I I}=4 \cdot r \cdot S_{\mathrm{lim}}^{I I I}=4 \cdot 0.055 \cdot 2 \cdot 58,58=18.2 \mathrm{kNm}$ (cf. Figure 10, $S_{\lim }^{I I I}=a_{S}-$ for curve II). Thus, for example, for the values $W / W_{\lim }^{I I I}=0.275$ and $M / M_{\lim }^{I I I}=$ 0.325 , the diagram in Figure 26 quotes, interpolating linearly, the values of both reduction coefficients, namely $v_{W}^{I I I}=0.81$ and $v_{M}^{I I I}=0.89$.

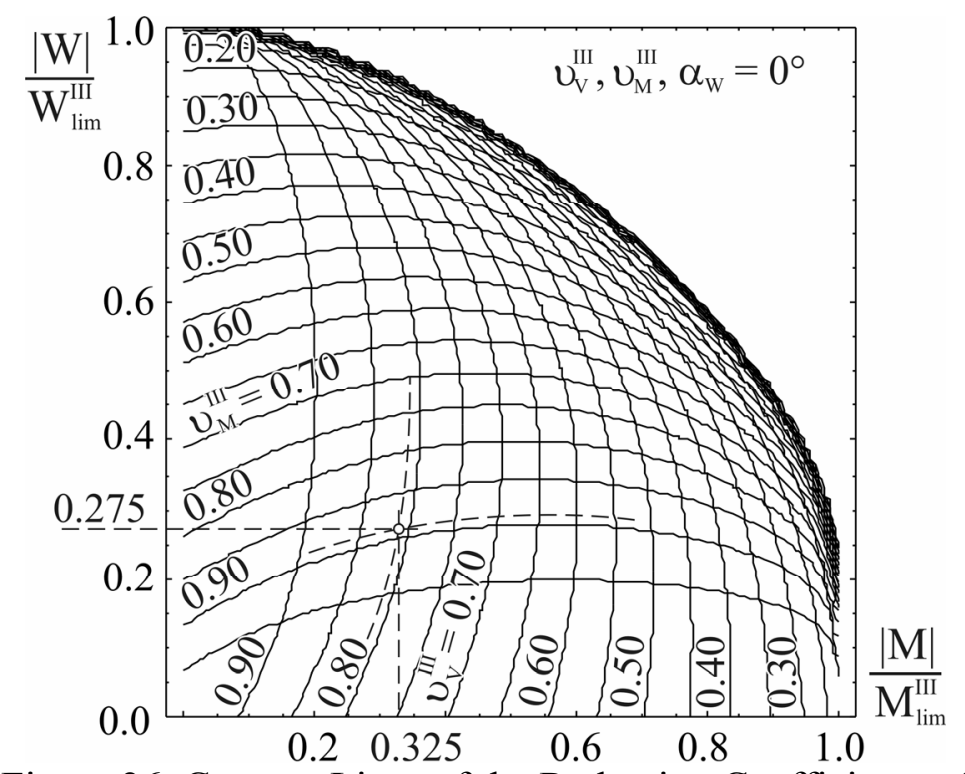

Figure 26. Contour Lines of the Reduction Coefficients of the Rigidities $v_{M}^{I I I}$ and $v_{W}^{I I I}$ in a 5-Blind-bolt Joint, [5]

\subsection{Analysis of the Results of Calculations}

In the static calculations of the frame several variants of combined loads were taken into account; considering the load-carrying capacity of the bars and nodes, of much importance proved to be the variant I (dead load of the frame, covering, walls, installations, snow in zone II, temperature), variant 2 (constant loads, wind in zone II) and variant 3 (variant I plus wind). Table 2 provides a comparison of selected results of static calculations for a frame with rigid, flexible and articulated nodes, loaded according; to variant 1 . The values of the forces $M, H$ and $V$ in the bars are quoted for two kinds of flexible joints: in column 4 the rotational rigidity and two rigidities corresponding to the mutual displacement of the joined walls in the direction of the loads $V$ and $H$ have been introduced, disregarding the reduction coefficients of rigidity; in column 5 the rigidities were calculated applying the formulae Eq. $14 \div$ Eq. 16, i.e. taking into account the values of the reduction coefficients $v_{W}$ and $v_{M}$, quoted in Table 3 (numbers above 100 correspond to the 
symmetrical nodes of the frame). The values of the reduction coefficients and are contained within the range $0.79 \leq v_{W} \leq 1.0$ and $0.89 \leq v_{M} \leq 1.0$.

Table 2. Results of Statistical Calculations Concerning a Frame with Rigid, Flexible and Articulated Nodes

\begin{tabular}{|c|c|c|c|c|c|}
\hline \multirow{3}{*}{$\begin{array}{l}\text { No. of } \\
\text { the } \\
\text { bar/ } \\
\text { node }\end{array}$} & \multirow{3}{*}{$\begin{array}{l}\text { Forces } \\
H, V[\mathrm{kN}] \\
\text { moment } \\
M[\mathrm{kNm}]\end{array}$} & \multicolumn{4}{|c|}{$\begin{array}{l}\text { Values } M, H, V \text { in the bars } \\
\text { of a frame with nodes }\end{array}$} \\
\hline & & \multirow[b]{2}{*}{ rigid } & \multicolumn{2}{|l|}{ flexible } & \multirow[b]{2}{*}{ articulatec } \\
\hline & & & $\begin{array}{l}\text { no } \\
\text { reduction } \\
\text { of rigidity }\end{array}$ & $\begin{array}{l}\text { reduced } \\
\text { rigidity }\end{array}$ & \\
\hline 1 & 2 & 3 & 4 & 5 & 6 \\
\hline $2 / 2$ & $\mathrm{M}$ & -2.1 & -2.7 & -3.0 & 0 \\
\hline \multirow{3}{*}{$2 / 3$} & $\mathrm{M}$ & 3.2 & 9.6 & 9.9 & 45.10 \\
\hline & $\mathrm{H}$ & 56.7 & 56.7 & 56.7 & 56.67 \\
\hline & $\mathrm{V}$ & 1.4 & 2.9 & 3.0 & 10.23 \\
\hline \multirow{3}{*}{$3 / 3$} & $\mathrm{M}$ & 17.6 & 22.7 & 22.9 & 45.10 \\
\hline & $\mathrm{H}$ & 50.2 & 50.0 & 50.0 & 50.34 \\
\hline & $\mathrm{V}$ & -123.8 & -126.9 & -126.7 & -148.87 \\
\hline \multirow{3}{*}{$3 / 4$} & $\mathrm{M}$ & -19.6 & -15.4 & -15.1 & 0 \\
\hline & $\mathrm{H}$ & 49.7 & 49.5 & 50.0 & 49.84 \\
\hline & $\mathrm{V}$ & -123.8 & -126.9 & -126.7 & -148.87 \\
\hline \multirow{3}{*}{$5 / 4$} & $\mathrm{M}$ & -21.5 & -17.3 & -17.0 & -1.88 \\
\hline & $\mathrm{H}$ & 130.8 & 133.8 & 133.6 & 155.25 \\
\hline & $\mathrm{V}$ & 15.7 & 14.9 & 14.8 & 10.15 \\
\hline \multirow{3}{*}{$9 / 3$} & $\mathrm{M}$ & -14.4 & -13.1 & -13.0 & 0 \\
\hline & $\mathrm{H}$ & -125.2 & -129.8 & -129.7 & -159.09 \\
\hline & $\mathrm{V}$ & 5.7 & 5.9 & 6.0 & 5.61 \\
\hline
\end{tabular}

Table 3. Values of the Reduction Coefficients of the Rigidities $v_{W}$ and $v_{M}$

\begin{tabular}{|l|l|l|l|l|}
\hline \multirow{2}{*}{ No. of the nodes } & \multicolumn{2}{|l|}{ variant I } & \multicolumn{2}{l|}{ variant II } \\
\cline { 2 - 5 } & $v_{M}$ & $v_{W}$ & $v_{M}$ & $v_{W}$ \\
\hline 2 & 0.950 & 0.990 & 1.000 & 0.880 \\
102 & 0.970 & 0.970 \\
\hline 3 & 0.920 & 0.830 & 0.950 & 0.920 \\
103 & 0.920 & 0.790 & 0.950 & 0.835 \\
\hline 4 & 0.955 & 0.890 \\
104 & 0.930 & 0.935 & 0.950 & 0.950 \\
\hline 8 & 0.950 & 0.960 \\
108 & 0.890 & 1.000 & 0.910 & 1.000 \\
\hline 12 & & & 0.910 & 1.000 \\
112 & \multicolumn{3}{|l}{} \\
\hline
\end{tabular}

In the case of the frame bars the conditions of the load-carrying capacity have been checked, which have been satisfied as follows (cf. Figure 21): in the bottom section (bar 2) and upper section (bar 3) of the pillar $0.932<1.0$ and $0.862<1.0$, respectively, and in the flanges of the upper spandrel beam (bar 5) and the bottom flange (bar 9) $0.790<1.0$ and $0.580<1.0$, respectively. Table 4 presents the values of maximum vertical and horizontal displacements of the spandrel beam on the level of the quoins, which do not exceed the boundary values. 
Table 4. Values of Vertical and Horizontal Displacements in the Spandrel Beam at the Quoins of a Frame with Rigid, Flexible and Articulated Nodes

\begin{tabular}{|l|l|l|l|l|l|l|}
\hline \multirow{2}{*}{$\begin{array}{l}\text { No. } \\
\text { Nof the } \\
\text { nodes }\end{array}$} & $\begin{array}{l}\text { Displace- } \\
\text { ments }\end{array}$ & rigid & \multicolumn{3}{|l|}{ Displacements in a frame with nodes [mm] } & \\
\cline { 3 - 6 } & & $\begin{array}{l}\text { flexible } \\
\text { no } \\
\text { reduction } \\
\text { of rigidity }\end{array}$ & $\begin{array}{l}\text { articulate } \\
\text { rigidity } \\
\text { reduced } \\
\text { displace- } \\
\text { ments } \\
{[\mathrm{mm}]}\end{array}$ \\
\hline 9 & vertical & 13.5 & 20.5 & 21.6 & 39.3 & 72.0 \\
\hline 3 & $\begin{array}{l}\text { horizonta } \\
1\end{array}$ & 6.1 & 13.5 & 13.7 & 544.4 & 32.0 \\
\hline
\end{tabular}

Figure 27 presents a comparison of the percentage changes of the values of bending moments concerning the cases quoted in columns 3 and 5 in Table 2. The differences are considerable and in the average they are as large as some score of percent. Thus, for instance, in the span of bar 6 (cf. Figure 21) the values of the moments are in a frame with flexible nodes larger by $39 \%$ in relation to a frame with rigid nodes.

a)

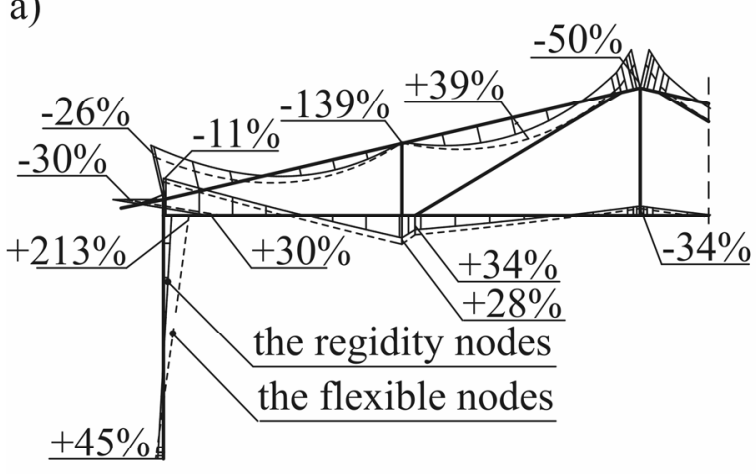

b)

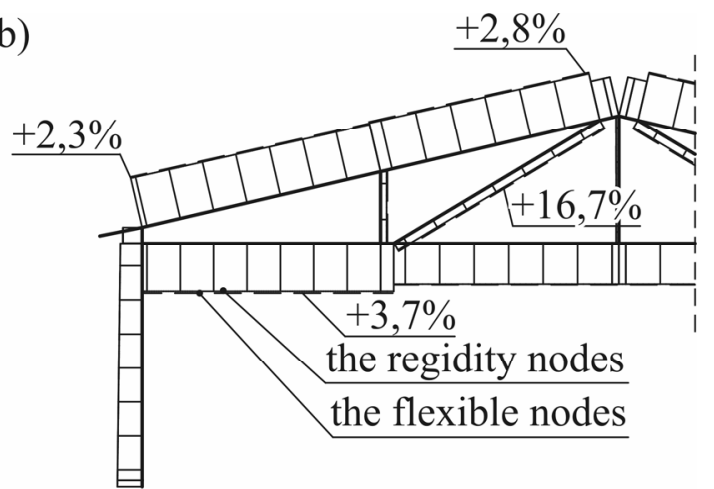

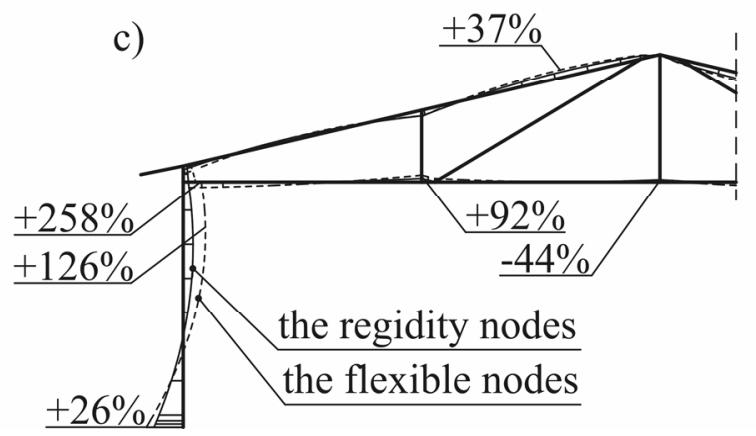

Figure 27. Diagrams of the Forces in the Bars of the Frame: a) Bending Moments in Variant 1 of Loads, b) Axial Forces in Variant 1 of Loads, c) Bending Moments in Variant 2 of Loads 


\section{CONCLUSIONS}

The results of single-cut joints with bolts, investigated by the author, including alternately loaded joints, are characterized by considerable scatters within the frame of identical cases of constructions. These scatters cannot be eliminated - as has been found - by a better accuracy in the construction of the joints, although their rigidity can be improved by embedding the bolts in holes with smaller diameters, within the range recommended by the producers of the joints.

Keeping all this in mind, the suggested way of calculating the joints may be considered to be accurate enough. If the relation between the load $S_{i}$, the value of the torque moment $M_{i \phi}$ and the angular displaceraent $\phi$, were known, which might be achieved only experimentally, it would become possible to modify the set of equations and to solve it once again, assessing - basing on the example of a four-blind-bolt joint or eight-blind-bolt joint - how much the friction forces can improve the compatibility of experimental and numerical results.

Referring to the results obtained in calculations of a frame with flexible nodes it has been found that the differences between the values of the bending moments, occurring in the bars of the frame connected with each other rigidly or flexibly, are considerable.

The rather small effect of the reduction coefficients $v_{M}$ and $v_{W}$ on the values of internal forces in the bars of the frame result from redimensioning of the 5-blind-bolt joints in the nodes 2,8 arid 12 , which had too large reserves. The interaction of three rigidities would mean a greater share in the static work of the frame, if the joints in these nodes were designed with a respectively reduced number of links, as the values of the coefficients $v_{M}$ and $v_{W}$ in Table 2 suggest; in some nodes the values of the rigidity of the joints are reduced by $11 \%$ at bending and $21 \%$ due to the effect of the longitudinal force.

Contour lines of the reduction coefficients ought to be determined for several typical joints, e.g. 2-, 3- and 4-blind-bolt joints. Only then will it be possible to design the considered construction of the frame with an adequately chosen smaller number of links in the respective joints.

The important problem of alternate loads of the knuckle joints has not been taken into account in the calculations of the frame. Only one load cycle has been taken into account, resulting from the impact of the wind. Obviously, the changing the direction of the construction results in a change of the values and directions of the bending moments $M$ and shearing forces $W$ in the joints, particularly in the quoins of the considered frame.

The joints taking alternately over the exerted forces $\pm M$ and $\pm W$ behave depending on the course of the functions which describe the hysteresis loops, connected with changes of the rigidity of the joints.

In order to find out the shapes of the hysteresis curves, alternately loaded joints were investigated, including those stretched axially and bent (cf. Figure 8).

It has also been noticed that when the direction of the wind changes, the joints in the quoins may instantaneously attain a zero rigidity.

The problem concerning the effect of alternate loads on the behaviour of the considered joints requires a new analytical approach and also a new computer programme, which would permit to analysis properly the statics and strength of the construction. In the presented calculations of the frame the applied Robot Millennium, v.15 programme [9] did not facilitate such an analysis.

The feasibility of applying FEM for the purpose of testing the given joints cannot be excluded; in such a case the results of the numerical analysis may be compared with the results obtained by means of the analytical method suggested in the present paper. 
It should be noticed that modelling any bent and sheared multi-blind-bolt joint in compliance with FEM may prove to be rather troublesome. A complete model permitting to obtain comparable results ought to be a spatial model. For the sake of simplification, e.g. a two-stage procedure should be applied: first the whole joint should be modelled applying elements of a lower order, i.e. "flat elements" (2D), and then "lump element" (3D) should be introduced into the analysis in the form of the separate surrounding for each single bolt, taking into account the respective boundary conditions. Of much importance would also be, among others, such effects as contact problems, the incomplete isotropy of the material that is to be joined, the fissures resulting from constant deformations as well as sliding and journal frictions occurring in the loaded joints.

Keeping all this in mind we may assume that a numerical analysis carried out by means of FEM would then involve the necessity of formulating untypical elements.

The problems of the effect of alternate loads on the behaviour of bar structures with single-cut joints and the elaboration of an FEM method for numerical investigations of such joints are topics which the author of the present report intends to deal with in the nearest future.

\section{REFERENCES}

[1] Wuwer, W., "Investigations and Calculation of Lap Joints with Special Blind Bolts", Polish Academy of Sciences, Archives of Civil Engineering, Volume LI, Issue 2. Warszawa, 2005, pp. $253 \div 280$.

[2] Wuwer, W., "Flexible Joints with Blind Bolts in Thin-walled Bar Constructions", Zeszyty Naukowe Politechniki Śląskiej Nr 1710 (z. 105), (Scientific Fascicles of the Silesian University of Technology). Gliwice, Poland, 2006.

[3] Technical Certificate of the Institute of Civil Engineering No. AT-15-3487/99, Bolts produced by Huck, 1999.

[4] Wuwer, W, The Effort of An Asymmetric Joint with Blind-bolts of Sheet-metal Sections. Proceedings of XITH International Conference on Metal Structures "Progress in Steel, Composite and Aluminium Structures", (ICMS-2006). Rzeszow, Poland, 2006, pp. 190 $\div 191$.

[5] Wuwer, W., Walentynski, R., "Interaction Relations in the Model of the Lap Joints of Thin-walled Structure under Complex Load State", Proceedings of International Colloquium of IASS Polish Chapter: Lightweight Structures in Civil Engineering, Warszawa, Poland,

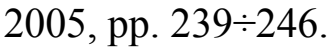

[6] Recommendations for Steel Construction, ECCS-TC7, The Design and Testing of Connections in Steel Sheeting and Sections. Constrado, No. 21, 1990.

[7] Dietrich, M., "Introduction to the Stochastic Theory of Machines", PWN (National Scientific Editors), Warszawa, Poland, 1972.

[8] Wuwer, W., Kowolik, B., "The Rigidity of Flexible Lap-joints Subjected to Complex Loads", Proceedings of XITH International Conference on Metal Structures, "Progress in Steel, Composite and Aluminium Structures", (ICMS-2006), Rzeszów, Poland, 2006, pp. $192 \div 193$.

[9] User manual, Robot Millennium, v.15, 2002.

[10] PN-B-03207, Steel Structures, Constructions of Section and Cold-formed Sheet-metal. Design and realization (Polish standard).

[11] Wuwer, W., Kowolik, B., "Frames of Thin-walled Sections with Flexible Nodes" (in Polish), Proceedings of 7th Symposium of the Cycle: New Achievements in Science and Technology in Civil Engineering. Rzeszów, Poland, 2005, pp. 355 366 . 